\title{
An Epilepsy-Associated KCNT1 Mutation Enhances Excitability of Human iPSC-Derived Neurons by Increasing Slack $\mathrm{K}_{\mathrm{Na}}$ Currents
}

\author{
- Imran H. Quraishi, ${ }^{1 \star}$ Shani Stern, ${ }^{2 *}$ Kile P. Mangan, ${ }^{3 *}$ Yalan Zhang, ${ }^{4}$ Syed R. Ali, ${ }^{4}$ Michael R. Mercier, ${ }^{1}$ \\ Maria C. Marchetto, ${ }^{2}$ Michael J. McLachlan, ${ }^{3}$ Eugenia M. Jones, ${ }^{3}$ Fred H. Gage, ${ }^{2}$ and ${ }^{-}$Leonard K. Kaczmarek $^{4,5}$ \\ ${ }^{1}$ Department of Neurology, Yale Comprehensive Epilepsy Center, Yale School of Medicine, New Haven, Connecticut 06520, ${ }^{2}$ Laboratory of Genetics-G, The \\ Salk Institute for Biological Studies, La Jolla, California 92037, ${ }^{3}$ FUJIFILM Cellular Dynamics, Inc., Madison, Wisconsin 53711, ${ }^{4}$ Department of \\ Pharmacology, Yale School of Medicine, New Haven, Connecticut 06520, and ${ }^{5}$ Department of Cellular and Molecular Physiology, Yale School of Medicine, \\ New Haven, Connecticut 06520
}

Mutations in the KCNT1 (Slack, $\mathrm{K}_{\mathrm{Na}} 1.1$ ) sodium-activated potassium channel produce severe epileptic encephalopathies. Expression in heterologous systems has shown that the disease-causing mutations give rise to channels that have increased current amplitude. It is not known, however, whether such gain of function occurs in human neurons, nor whether such increased $\mathrm{K}_{\mathrm{Na}}$ current is expected to suppress or increase the excitability of cortical neurons. Using genetically engineered human induced pluripotent stem cell (iPSC)-derived neurons, we have now found that sodium-dependent potassium currents are increased several-fold in neurons bearing a homozygous P924L mutation. In current-clamp recordings, the increased $\mathrm{K}_{\mathrm{Na}}$ current in neurons with the P924L mutation acts to shorten the duration of action potentials and to increase the amplitude of the afterhyperpolarization that follows each action potential. Strikingly, the number of action potentials that were evoked by depolarizing currents as well as maximal firing rates were increased in neurons expressing the mutant channel. In networks of spontaneously active neurons, the mean firing rate, the occurrence of rapid bursts of action potentials, and the intensity of firing during the burst were all increased in neurons with the P924L Slack mutation. The feasibility of an increased $\mathrm{K}_{\mathrm{Na}}$ current to increase firing rates independent of any compensatory changes was validated by numerical simulations. Our findings indicate that gain-of-function in Slack $\mathrm{K}_{\mathrm{Na}}$ channels causes hyperexcitability in both isolated neurons and in neural networks and occurs by a cell-autonomous mechanism that does not require network interactions.

Key words: action potential; EIMFS; epileptic encephalopathy; MMPSI; potassium channels; seizures

Significance Statement

KCNT1 mutations lead to severe epileptic encephalopathies for which there are no effective treatments. This study is the first demonstration that a KCNT1 mutation increases the Slack current in neurons. It also provides the first explanation for how this increased potassium current induces hyperexcitability, which could be the underlining factor causing seizures.

\section{Introduction}

Mutations of the Slack $\mathrm{K}^{+}\left(\mathrm{K}_{\mathrm{Na}} 1.1\right)$ channel lead to a highly intractable childhood epilepsy syndrome called malignant mi-

Received June 28, 2018; revised July 8, 2019; accepted July 17, 2019.

Author contributions: I.H.Q., K.P.M., F.H.G., and L.K.K. designed research;I.H.Q., S.S., K.P.M., Y.Z., S.R.A., M.R.M., M.C.M., and L.K.K. performed research; I.H.Q., S.S., K.P.M., Y.Z., S.R.A., M.R.M., M.C.M., and L.K.K. analyzed data; I.H.Q. wrote the first draft of the paper; I.H.Q., S.S., K.P.M., Y.Z., S.R.A., M.J.M., and L.K.K. edited the paper; K.P.M., M.J.M., and E.M.J. contributed unpublished reagents/analytic tools.

Acknowledgements: This work was supported by National Institutes of Health NS102239 to L.K.K. and a Swebilius Foundation Grant to I.H.Q.

K.P.M., M.J.M., and E.M.J. are employed by FUJIFILM Cellular Dynamics, Inc. The remaining authors declare no competing financial interests.

*I.H.Q., S.S., and K.P.M. contributed equally to the work

Correspondence should be addressed to Leonard K. Kaczmarek at leonard.kaczmarek@yale.edu. grating partial seizures of infancy (MMPSI), also called epilepsy of infancy with migrating focal seizures (EIMFS) (Barcia et al., 2012; Kim et al., 2014; Shimada et al., 2014; Vanderver et al., 2014; Møller et al., 2015; Mikati et al., 2015; Rizzo et al., 2016; Tang et al., 2016). This is a devastating epileptic encephalopathy with no effective treatments. Children with MMPSI experience scores of multifocal seizures per day (Coppola et al., 1995). They are profoundly intellectually disabled, and brain development halts at an infantile stage with many children remaining unable to speak or walk. Mortality is high, and sudden unexpected death in 
epilepsy (SUDEP) has been reported (Møller et al., 2015). Slack mutations have now also been associated with a spectrum of focal epilepsies including other infantile epileptic encephalopathies and later onset autosomal dominant nocturnal frontal lobe epilepsy (ADNFLE) (Heron et al., 2012; Martin et al., 2014; Møller et al., 2015; Ohba et al., 2015).

Slack, most recently termed $\mathrm{K}_{\mathrm{Na}} 1.1$ (Kaczmarek et al., 2017), is a sodium-activated potassium channel encoded by KCNT1 (Yuan et al., 2003; Kaczmarek, 2013). Functions attributed to the channel include regulation of neuronal bursting in sensory neurons (Tamsett et al., 2009; Nuwer et al., 2010; Biton et al., 2012; Lu et al., 2015) and maintaining temporal accuracy in auditory brainstem neurons (Yang et al., 2007). Slack has also been proposed to regulate neuronal development through interactions with the Fragile X Mental Retardation Protein (FMRP) and translational machinery (Brown et al., 2010; Zhang et al., 2012; Kim and Kaczmarek, 2014; Bausch et al., 2015).

In heterologous expression systems, epilepsy-causing mutations cause substantially increased Slack channel activity over that of WT channels with no change in the level of channel protein (Barcia et al., 2012; Kim et al., 2014). This gain-of-function is seen with a large variety of different mutations (Kim et al., 2014; Martin et al., 2014; Milligan et al., 2014). Although altered voltage and/or sodium dependence contribute in part to the increased current for a subset of mutations (Kim et al., 2014; Tang et al., 2016), for most mutations the level of increased current is too large to be explained by changes in these parameters (Kim et al., 2014). Evidence indicates that enhanced positive cooperativity between channels is a major factor that increases channel activity (Kim et al., 2014). However, it is not yet known whether similar gain-of-function occurs in neurons, or if high Slack currents directly enhance neuronal excitability. Slack-mediated $\mathrm{K}_{\mathrm{Na}}$ currents activate at relatively negative potentials (Santi et al., 2006; Yang et al., 2007), and increases in current near the resting potential would be expected to suppress rather than increase excitability.

Human induced pluripotent stem cell (hiPSC) technology offers a novel tool to advance our understanding of neurological diseases. hiPSCs surpass heterologous systems because regular, adjunct biology is conserved (Liu et al., 2013; LaMarca et al., 2018). In a wide variety of neurological disorders, hiPSCs have not only advanced understanding of disease mechanisms, but have also provided a more relevant avenue for drug screening (Tidball and Parent, 2016; Csobonyeiova et al., 2017; Gonzalez et al., 2017; Balan et al., 2018).

To understand how Slack mutations contribute to hyperexcitability, we have generated and evaluated a hiPSC-derived neuron line harboring an MMPSI-associated mutation known to have gain of function, P924L Slack (Milligan et al., 2014). The mutation was generated by nuclease-mediated engineering, allowing a true isogenic control. We characterized neurons derived from these cells using voltage-clamp recordings as well as multielectrode arrays (MEA) and current-clamp recordings to evaluate firing patterns and the properties of action potentials. Currentclamp recordings were performed at an earlier [days in vitro (DIV) after plating 7-8] and later (DIV after plating 14-16) maturation stage.

\section{Materials and Methods}

Generation of Slack P924L iPSC-derived neurons. Human neurons differentiated from induced pluripotent stem cells (iCell Neurons) were provided by FUJIFILM Cellular Dynamics. These cells were generated through a proprietary forebrain differentiation protocol developed by
Cellular Dynamics, resulting in a population of neurons without glial or oligodendrocyte cells. The cells have been characterized to demonstrate their similarity to primary neurons. Thawed neuron populations are $>95 \%$ pure neurons, rapidly form neural networks via functional synapses, and display long-term viability and reproducibility (Berry et al., 2015). They have previously been described and characterized including methods for plating and maintenance (Chai et al., 2012; Haythornthwaite et al., 2012; Chatzidaki et al., 2015). Gene expression and pharmacology closely resembles neonatal prefrontal cortex (Dage et al., 2014). To generate a KCNT1 P924L allelic variant, nuclease-mediated SNP alteration of the healthy control cell line was performed to introduce a site-specific mutation using proprietary licensed protocols, similar to prior efforts that generated disease-specific models of cardiomyocytes (Drawnel et al., 2014). The resulting cells have the P924L variant in both KCNT1 alleles.

Measurement of Slack expression. Cellular lysates were separated on $4-15 \%$ gradient SDS gels, transferred to nitrocellulose paper, probed overnight at $4^{\circ} \mathrm{C}$ with primary antibody as indicated. For Slack expression we used a custom polyclonal pan-Slack antibody (1:500) or GAPDH antibody (1:500, Santa Cruz Biotechnology) with goat anti-rabbit (\#7074, Cell Signaling Technology) HRP-conjugated secondary antibodies (1:1000 in 5\% milk solution). The Slack antibody was designed as a custom polyclonal antibody against the $\mathrm{C}$ terminus region of rSlack using the peptide sequence GCDVMNRVNLGYLQDEMNH (Brown et al., 2008). Generation of this rabbit polyclonal anti-pan-Slack IgG was performed by Biosynthesis. A stable rat Slack-expressing HEK cell line was used as a positive control for the antibody. Other membrane proteins were measured including Nav1.1 (1:1000, Alomone Laboratories), Kv1.1 (1:500, NeuroMab), BK (1:500, BD Bioscience), and Na,K-ATPase antibody (1:1000, Cell Signaling Technology, for normalization of membrane proteins).

Patch-clamp electrophysiology. Cells were plated on $12 \mathrm{~mm}$ glass coverslips that were transferred into a recording chamber. Whole-cell patchclamp recordings were performed in one preparation at 7-8 d after plating for current clamp and another preparation at 7-10 d after recording for voltage clamp and then repeated with a second preparation for current clamp at 14-16 d. Recordings were made from five coverslips for voltage-clamp and two coverslips for each of two preparations for current clamp. Pipette tip resistance was typically $2-4 \mathrm{M} \Omega$ for voltage-clamp and $10-15 \mathrm{M} \Omega$ for current clamp. Signals were amplified with an EPC-7 (HEKA) or a Multiclamp 700B (Molecular Devices) amplifier and recorded with Clampex 10.2 software (Molecular Devices). Data were acquired at a sampling rate of $2 \mathrm{kHz}$ (for voltage clamp) or $20 \mathrm{kHz}$ (for current clamp) and analyzed using Clampfit 10 (Molecular Devices) and MATLAB 2017b (The MathWorks). All measurements were conducted at room temperature.

For voltage-clamp recordings, the extracellular medium contained the following (in $\mathrm{mm}$ ): either $139 \mathrm{NaCl}$ or $139 \mathrm{~N}$-methyl-D-glucamine (NMDG), $5.4 \mathrm{KCl}, 1 \mathrm{CaCl}_{2}, 1 \mathrm{MgCl}_{2}$, and 10 glucose, with $\mathrm{pH} 7.3$, and patch electrodes were filled with (in $\mathrm{mM}$ ) $97.5 \mathrm{~K}^{+}$gluconate, $32.5 \mathrm{KCl}, 10$ HEPES, 1 EGTA, $2 \mathrm{MgCl}_{2}$. For current clamp, the extracellular recording medium contained the following (in mM): $139 \mathrm{NaCl}, 10 \mathrm{HEPES}, 4 \mathrm{KCl}, 2$ $\mathrm{CaCl}_{2}, 1 \mathrm{MgCl}_{2}, 10$ D-glucose (310 mOsm, $\mathrm{pH}$ 7.4), and patch electrodes were filled with internal solutions containing the following (in $\mathrm{mM}$ ): 130 $\mathrm{K}^{+}$gluconate, $6 \mathrm{KCl}, 4 \mathrm{NaCl}, 10 \mathrm{Na}$-HEPES, 0.2 K-EGTA, $0.3 \mathrm{GTP}, 2$ MgATP, 0.2 cAMP, 10 D-glucose, $0.15 \%$ biocytin and $0.06 \%$ rhodamine. The $\mathrm{pH}$ and osmolarity of the internal solutions were brought close to physiological conditions ( $\mathrm{pH} 7.3,290-300 \mathrm{mOsm}$ ).

For measurements of $\mathrm{K}_{\mathrm{Na}}$ currents, whole-cell voltage-clamp measurements were performed with cells held at $-70 \mathrm{mV}$ and given $600 \mathrm{~ms}$ voltage pulses in $10 \mathrm{mV}$ steps over a fixed range of -80 to $+70 \mathrm{mV}$. Recordings were obtained independently for cells in extracellular medium containing either $140 \mathrm{~mm} \mathrm{Na}^{+}$or $140 \mathrm{~mm}$ NMDG. Current traces from NMDG were averaged and subtracted from the individual current traces obtained from the $\mathrm{Na}^{+}$condition. The difference current at the end of the voltage pulse was considered to be the steady-state $\mathrm{K}_{\mathrm{Na}}$ current.

To quantify the total number of evoked action potentials, cells were held in current-clamp mode near $-60 \mathrm{mV}$ with a steady holding current, 
and current injections were given starting $12 \mathrm{pA}$ below the steady holding current, in a total of 20 depolarization steps, with $3 \mathrm{pA}$ increments and $400 \mathrm{~ms}$ in duration. Neurons that needed $>50 \mathrm{pA}$ to be held at $-60 \mathrm{mV}$ were discarded from the analysis.

Numerical simulations. Simulations of the effects of $\mathrm{K}_{\mathrm{Na}}$ currents on neuronal firing were performed using a simple one-compartment neuronal model comprising a $\mathrm{Na}^{+}$current $I_{\mathrm{Na}}$, a leak current $I_{\mathrm{L}}$, a voltagedependent $\mathrm{K}^{+}$current $I_{\mathrm{Kv}}$ and a $\mathrm{Na}^{+}$- activated $\mathrm{K}^{+}$current $I_{\mathrm{KNa}}$, with kinetic parameters based on previous simulations of the effects of $\mathrm{K}_{\mathrm{Na}}$ currents on firing patterns (Yang et al., 2007; Brown et al., 2008). Responses were simulated by integration of the equation $\mathrm{C} \mathrm{dV} / \mathrm{dt}=I_{\text {ext(t) }}-$ $I_{\mathrm{Na}}-I_{\mathrm{Kv}}-I_{\mathrm{KNa}}-I_{\mathrm{L}}$, where stimuli $I_{\text {ext(t) }}$ were presented as a single step current $(0.01-0.04 \mathrm{nA}, 100 \mathrm{~ms})$. Equations and parameters for $I_{\mathrm{Na}}, I_{\mathrm{Kv}}$, and $I_{\mathrm{L}}$ were similar to those used in previous simulations on neuronal firing patterns (Liu and Kaczmarek, 1998; Wang et al., 1998; Richardson and Kaczmarek, 2000; Macica et al., 2003; Bhattacharjee et al., 2005; Song et al., 2005; Yang et al., 2007; Kaczmarek, 2012). Specifically, $I_{\mathrm{L}}$ and $I_{\mathrm{Na}}$ were given by the equations $I_{\mathrm{Na}}=\mathrm{g}_{\mathrm{Na}} \mathrm{m}^{3} \mathrm{~h}(\mathrm{~V}-50)$ and $I_{\mathrm{L}}=\mathrm{g}_{\mathrm{L}}(V+80)$ respectively. Kinetic parameters for the evolution of the variables $\mathrm{m}$ and $\mathrm{h}$ were $\mathrm{g}_{\mathrm{Na}}=1.5 \mu \mathrm{S}, k_{\alpha \mathrm{m}}=76.4 \mathrm{~ms}^{-1}, \eta_{\mathrm{am}}=0.037 \mathrm{mV}^{-1}, k_{\beta \mathrm{m}}=6.93$ $\mathrm{ms}^{-1}, \eta_{\mathrm{bm}}=-0.043 \mathrm{mV}^{-1}$, and $k_{\alpha \mathrm{h}}=0.000135 \mathrm{~ms}^{-1}, \eta_{\mathrm{ah}}=-0.1216$ $\mathrm{mV}^{-1}, k_{\beta \mathrm{h}}=1.237 \mathrm{~ms}^{-1}$ and $\eta_{\mathrm{bh}}=0.0384 \mathrm{mV}^{-1}$. The voltagedependent $\mathrm{K}^{+}$current $I_{\mathrm{Kv}}$ was given by the equation $I_{\mathrm{Kv}}=\mathrm{g}_{\mathrm{Kv}} l r(\mathrm{~V}+$ 80 ), with the parameters for the evolution of the gating particles $l$ and $r$ given by $\mathrm{g}_{\mathrm{Kv}}=0.03 \mu \mathrm{S}, k_{\alpha 1}=1.2 \mathrm{~ms}^{-1}, \eta_{\alpha 1}=0.03512 \mathrm{mV}^{-1}, k_{\beta 1}=$ $0.2248 \mathrm{~ms}^{-1}, \eta_{\beta 1}=-0.0319 \mathrm{mV}^{-1}, k_{\alpha \mathrm{r}}=0.0438 \mathrm{~ms}^{-1}, \eta_{\alpha \mathrm{r}}=-0.0053$ $\mathrm{mV}^{-1}, k_{\beta \mathrm{r}}=0.0562 \mathrm{~ms}^{-1}$ and $\eta_{\beta \mathrm{r}}=-0.0047 \mathrm{mV}^{-1}$. The capacitance C was $0.1 \mathrm{nF}$ and the leakage conductance $\mathrm{g}_{\mathrm{L}}$ was $0.002 \mu \mathrm{S}$.

To simulate Slack currents, $I_{\mathrm{KNa}}$ was given by the equation $I_{\mathrm{KNa}}=$ $\mathrm{g}_{\mathrm{KNa}} \mathrm{n}^{2} \mathrm{~s}^{4}(\mathrm{~V}+80)$, where the variable $n$ describes voltage dependence and is governed by the kinetic parameters, $k_{\alpha \mathrm{n}}=1.38 \mathrm{~ms}^{-1}, \eta_{\alpha \mathrm{n}}=$ $-0.0105 \mathrm{mV}^{-1}, k_{\beta \mathrm{n}}=0.5763 \mathrm{~ms}^{-1}$ and $\eta_{\beta \mathrm{n}}=-0.0355 \mathrm{mV}^{-1}$ (Brown et al., 2008). The conductance $\mathrm{g}_{\mathrm{KNa}}$ was varied between 0 and $4.0 \mu \mathrm{S}$.

The variable s represents the proportion of Slack subunits activated by $\mathrm{Na}^{+}$ions at the cytoplasmic face of the Slack channel. As in previous simulations, changes in $\mathrm{Na}^{+}$concentration at the cytoplasmic face of the $\mathrm{K}_{\mathrm{Na}}$ channels, $\left[\mathrm{Na}^{+}\right]_{\mathrm{i}}$, were modeled by the equation $\mathrm{d}\left[\mathrm{Na}^{+}\right]_{\mathrm{i}} / \mathrm{dt}=\mathrm{aI} I_{\mathrm{Na}}$ $+\mathrm{a}^{\prime}-\mathrm{b}\left[\mathrm{Na}^{+}\right]_{\mathrm{i}}$, where the kinetic constants a and a' represent $\mathrm{Na}^{+}$entry though voltage-dependent $\mathrm{Na}^{+}$channels and $\mathrm{a} \mathrm{Na}^{+}$leak, respectively, and $b$ determines the rate of pumping of $\mathrm{Na}^{+}$out of the cell. In the model cell, $\mathrm{a}=2.5, \mathrm{a}^{\prime}=0.25 \mathrm{mM} \mathrm{ms}^{-1}$ and $\mathrm{b}=0.1 \mathrm{~ms}^{-1}$. The variable $\mathrm{s}$ represents the proportion of Slack channels activated by $\left[\mathrm{Na}^{+}\right]_{\mathrm{i}}$, and evolves according to the equation $\mathrm{ds} / \mathrm{dt}=k_{\mathrm{f}}\left[\mathrm{Na}^{+}\right]_{\mathrm{i}}(1-\mathrm{s})-k_{\mathrm{b}} \mathrm{s}$, with $k_{\mathrm{f}}=$ $0.014 \mathrm{~mm}^{-1} \mathrm{~ms}^{-1}$ and $k_{\mathrm{b}}=0.4 \mathrm{~ms}^{-1}$.

Multielectrode array recordings. WT and Slack P924L-expressing iPSCderived neurons were thawed and plated in individual clusters ("dots") of 80,000 cells in a 48-well MEA plate (Axion Biosystems). Cells were cultured in BrainPhys neuronal medium (Stem Cell Technologies) and underwent $50 \%$ media change every $2-3 \mathrm{~d}$. Eight-minute long recordings were made on DIV 11 post-plating ( $n=24$ per group). Raw extracellular voltage recordings were processed on a Maestro 768 channel system (Axion) with $200-4 \mathrm{kHz}$ Butterworth filter. Action potentials were captured on each channel via a 6 SD detection limit. Analysis of MEA spike trains was performed via Neural Metric (Axion). Burst analysis was based on a Poisson Surprise algorithm that identified clusters with a surprise factor threshold $S \geq 10$ (Legéndy and Salcman, 1985). Synchrony between channels was assessed using a binless measure of cross-correlation (Paiva et al., 2010).

Experimental design and statistical analysis. Action potential shape analysis: The first evoked action potential was used for spike shape analysis (with the lowest injected current needed for eliciting an action potential). Spike threshold was the membrane potential at which the slope of the depolarizing membrane potential increased drastically, resulting in an action potential (the first maximum in the second derivative in $\mathrm{dV}_{\mathrm{m}} / \mathrm{dt}$ vs $\mathrm{V}_{\mathrm{m}}$ phase space). The $5 \mathrm{~ms}$ AHP amplitude was calculated as the difference between the threshold for spiking and the value of the membrane potential $5 \mathrm{~ms}$ after the potential returned to cross the threshold value at the end of the action potential. The spike amplitude was calculated as the difference between the maximum membrane potential during a spike and the threshold. Action potential width was calculated as the time it took the membrane potential to reach half the spike amplitude in the rising part of the spike to the descending part of the spike (full width at half maximum), using the threshold time as the lower limit.

Differences between groups for the steady-state $\mathrm{K}_{\mathrm{Na}}$ current as measured by voltage clamp were compared using repeated-measures ANOVA followed by two-tailed Student's $t$ test with Holm-Sidak correction for multiple comparisons. Morphological features of action potentials from current-clamp experiments were compared by two-tailed Student's $t$ test. Spike counts were compared using a Mann-Whitney $U$ test. Exact sample sizes and significance values are reported for all statistical tests. Means are reported with SEM unless noted otherwise.

\section{Results}

\section{The P924L mutation does not alter Slack, BK, or Nav1.1 channel expression in neurons}

We compared Slack expression in human iPSCs that were differentiated into neurons. A mutant cell line expressing the P924L Slack mutation was engineered from WT cells using nucleasemediated engineering to ensure an isogenic control. Both cell lines were plated using two different methods. Conventional uniform plating of 80,000 cells on $12 \mathrm{~mm}$ glass coverslips was used to provide isolated cells that could be used for patch-clamp electrophysiology. The cells were also plated in high density "dots" of 60,000 cells in a single large cluster. These provided a high density of synaptic connections that were used for multielectrode array (MEA) recordings. Slack protein was expressed in both WT and Slack P924L cell lines as measured by Western blotting using a previously described "pan-Slack" antibody (Brown et al., 2008). The quantity of Slack protein measured by Western blotting was similar in the two cell types by densitometry. Moreover, the method of plating did not affect the level of channel expression (Fig. 1A).

As a screen for compensatory changes in other ion channels, we also measured the expression of BK channels, calciumdependent $\mathrm{K}^{+}$channels which are structurally and functionally similar to Slack, and Nav1.1 channels, because sodium entry during action potentials is suspected to be intricately linked to the activation of $\mathrm{K}_{\mathrm{Na}}$ currents. There was no obvious visual difference in either of these channels by Western blotting (Fig. 1B). By densitometry no significant differences were identified in Nav1.1 $(p=0.45, n=7), \mathrm{Kv} 1.1(p=0.19, n=7)$, or BK $(p=0.73, n=$ 10) expression between P924L and WT cell lysis products at DIV12 (Student's $t$ test).

\section{P924L Slack-expressing neurons have increased $\mathrm{K}_{\mathrm{Na}}$ currents} Whole-cell voltage-clamp measurements were first performed using physiological internal and external media with the extracellular medium containing $139 \mathrm{~mm} \mathrm{Na}^{+}$ions. Cells were held at $-70 \mathrm{mV}$ and stepped to potentials between -80 to $+70 \mathrm{mV}$ for $600 \mathrm{~ms}$. Under these conditions, both isogenic control and P924L Slack-expressing neurons displayed a rapid inward current (consistent with a voltage-activated sodium current) followed by a large, slowly inactivating outward current (Fig. 2A). The outward currents measured in cells expressing P924L Slack were significantly larger than those in cells with the WT channel at all test potentials above $+10 \mathrm{mV}(n=17$; Fig. $2 D)$.

The experiment was then repeated using external medium in which $139 \mathrm{~mm} N$-methyl-D-glucamine (NMDG) was substituted for $\mathrm{Na}^{+}$ions. In this medium, the fast inward current was abolished, and the slower outward current was decreased. In this $\mathrm{Na}^{+}$-free condition, there was no statistically significant difference in the amplitude of the outward current between the P924L Slack cells and WT cells (Fig. $2 B, E$ ). 
A
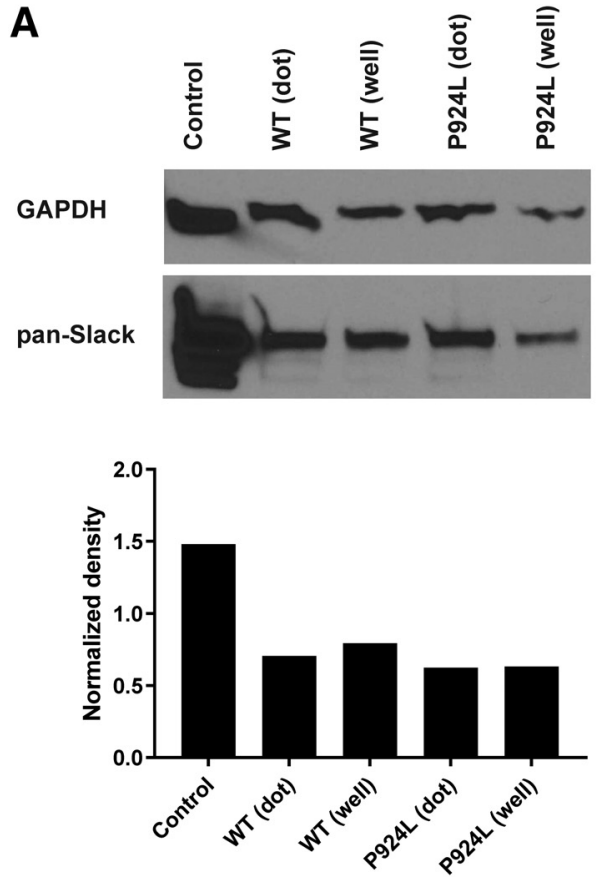

B
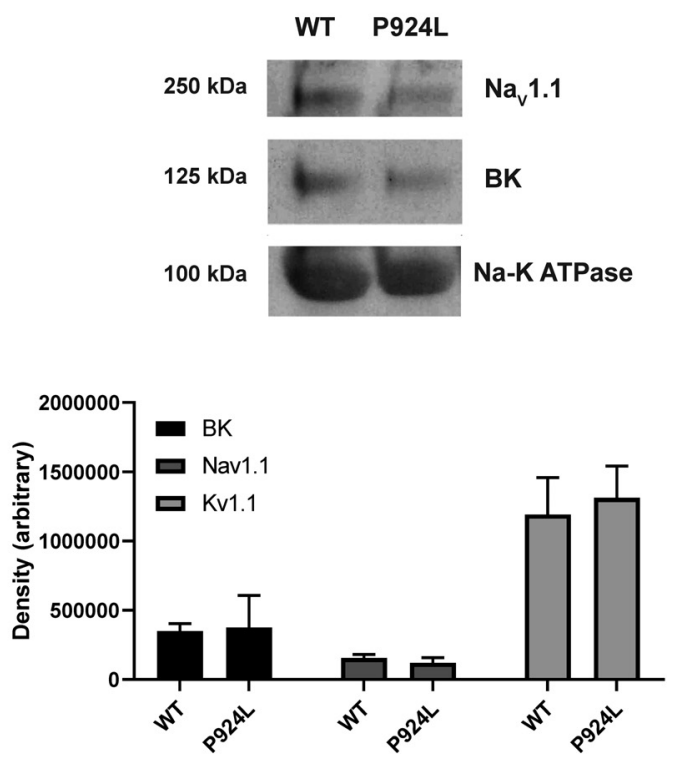

Figure 1. A, Slack expression measured by Western blot via a custom antibody specific for Slack and targeted to multiple epitopes (Brown et al., 2008) is similar in P924L and WT cells regardless of cell plating method. A stable rat Slack expressing cell line is used as control. B, No significant differences were seen in normalized Nav1.1 ( $p=0.45, n=7), \operatorname{Kv1.1}(p=0.19, n=7)$, or BK ( $p=$ $0.73, n=10$ ) expression between P924L and WT preparations (Student's $t$ test of densitometry values).

To isolate the $\mathrm{Na}^{+}$-dependent outward current, traces from cells in NMDG were averaged and subtracted from the traces obtained in the external $\mathrm{Na}^{+}$medium. The difference current at the end of the voltage pulses, corresponding to the steady-state $\mathrm{K}_{\mathrm{Na}}$ current, was substantially increased by the mutation, by as much as 20-fold over that in WT neurons (Fig. 2C,F).

The differences between the outward currents in WT and P924L Slack cell lines were most evident at more positive voltage steps, consistent with a voltage-activated current. At the upper limit of $+70 \mathrm{mV}$, for example, the outward current in the $\mathrm{Na}^{+}$free, NMDG-containing medium was not significantly different between WT $(0.75 \pm 0.13 \mathrm{nA})$ and the mutation $(0.80 \pm 0.070$ $\mathrm{nA} ; p=0.99, n=18$, Student's $t$ test with Holm correction). In contrast the outward current in the presence of extracellular $\mathrm{Na}^{+}$ was $0.68 \pm 0.080 \mathrm{nA}$ for WT cells compared with $1.07 \pm 0.16 \mathrm{nA}$ for the mutation $\left(p=9.5 \times 10^{-5}, n=17\right.$, Student's $t$ test with Holm correction). The corresponding $\mathrm{K}_{\mathrm{Na}}$ current estimates were $-0.065 \pm 0.080 \mathrm{nA}$ for WT and $0.277 \pm 0.156 \mathrm{nA}$ for the mutation $\left(p=1.1 \times 10^{-3}, n=17\right.$, Student's $t$ test with Holm correction).

Early maturation P924L Slack-expressing neurons have briefer, more numerous evoked action potentials

To compare the firing properties of individual P924L Slack and WT neurons at DIV $7-8$, the resting potential of all cells was adjusted to $-60 \mathrm{mV}$ in the current-clamp mode, using a small steady holding current. The cells were then hyperpolarized and depolarized with $400 \mathrm{~ms}$ current injections applied in $3 \mathrm{pA}$ increments.

We first compared the characteristics of the earliest action potential triggered by a suprathreshold depolarizing current. (Fig. 3A). The width of action potentials (full width at half maximum from the identified threshold potential) was significantly shorter in the P924L neurons $(8.32 \pm 0.66 \mathrm{~ms}$ for WT, $5.87 \pm$ $0.61 \mathrm{~ms}$ for P924L, $p=0.0128, n=22$, Student's $t$ test; Fig. $3 A$ ). In addition, the maximal afterhyperpolarization depth after the first threshold action potential was increased in neurons bearing the P924L mutation $(5.62 \pm 1.05 \mathrm{mV}$ for WT, $10.40 \pm 1.27 \mathrm{mV}$ for P924L, $p=0.0105, n=22$, Student's $t$ test). These changes are evident in representative recordings of action potentials at the onset of the depolarizing step (Fig. $3 B, C$, insets).

Some other characteristics of the response to depolarizing and hyperpolarizing steps did not show a significant difference between WT and P924L Slack cells. The action potential threshold, as calculated from the second derivative of a $\mathrm{dV}_{\mathrm{m}} / \mathrm{dt}$ vs $\mathrm{V}_{\mathrm{m}}$ plot, was similar between the two cell types $(-19.3 \pm 1.6 \mathrm{mV}$ in WT vs $-21.7 \pm 1.1 \mathrm{mV}$ for P924L, $p=0.244, n=26$, Student's $t$ test). The amplitudes of action potentials as measured from the holding potential were not appreciably different $(72.12 \pm 2.17$ for WT, $75.68 \pm 2.24$ for mutant, $p=0.43, n=26$, Student's $t$ test). We did not identify any significant difference in input resistance (WT $0.395 \pm 0.100 \mathrm{G} \Omega / \mathrm{pF}, \mathrm{P} 924 \mathrm{~L} 0.230 \pm 0.038 \Omega / \mathrm{pF}, p=0.14$, $n=22$, Student's $t$ test), which was calculated from the change in voltage in response to the range of subthreshold hyperpolarizing current pulses in the current-clamp mode.

The number of action potentials evoked by $400 \mathrm{~ms}$ depolarizing currents was greatly increased in the P924L Slack-expressing neurons. In control neurons, depolarizing currents elicited by $400 \mathrm{~ms}$ current steps over the range of 6 to $40 \mathrm{pA}$ above the action potential threshold current usually evoked only a single action potential (Fig. $3 A, B$ ). In contrast, in Slack P924L cells, the same currents typically evoked two to three action potentials (Fig. $3 \mathrm{~A}, \mathrm{C}$ ). For example, at $30 \mathrm{mV}$ above threshold, there were $1.10 \pm$ 0.10 evoked action potentials in WT and $2.17 \pm 0.42$ in P924 cells (Fig. $3 A$ ). The maximum number of action potentials that could be elicited in each cell over the entire range of current step amplitudes (Fig. 3A) was a median of 1 for WT neurons (range 1-4) and 4 for P924L Slack neurons (range 1-6), corresponding to a highly significant increase ( $p=0.0005, n=26$, Mann-Whitney $\mathrm{U}$ ).

During a train of action potentials evoked by a depolarizing current, changes in action potential height and width were evi- 
A $139 \mathrm{mM}$ $\mathrm{Na}^{+}$
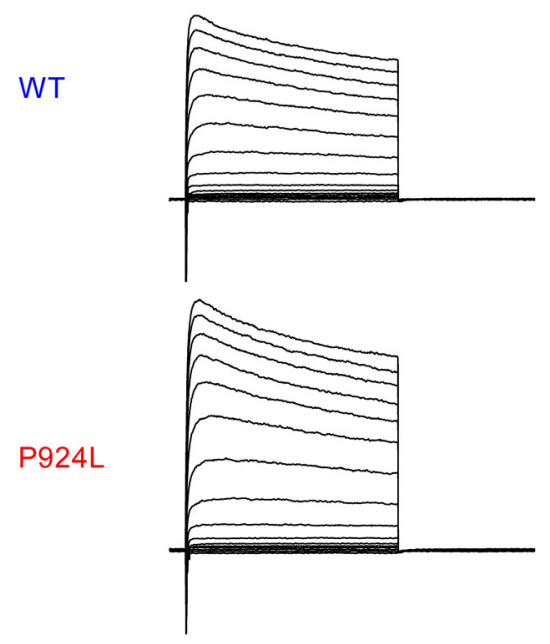

B

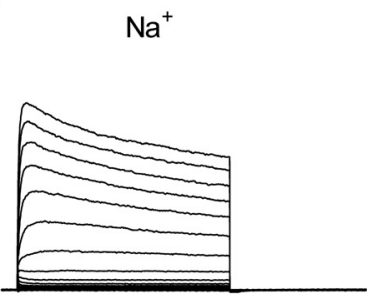

C

Difference
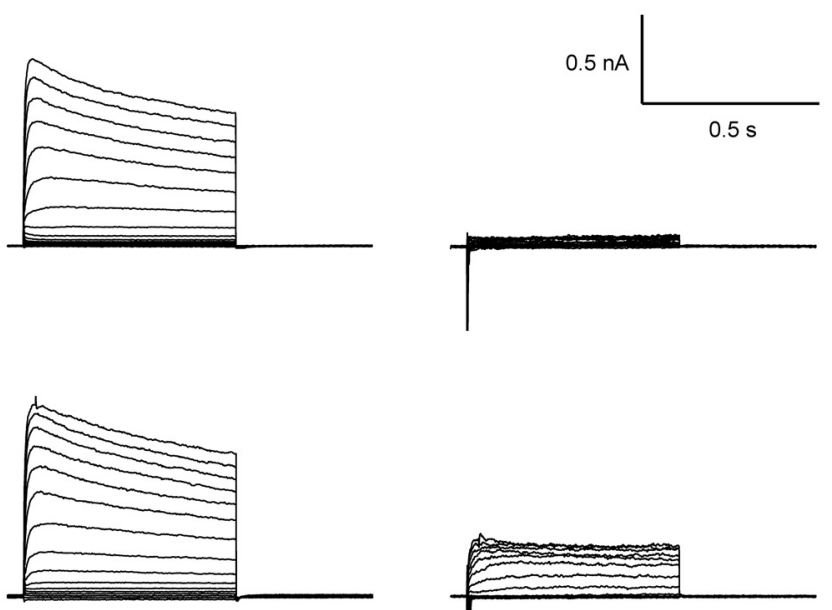
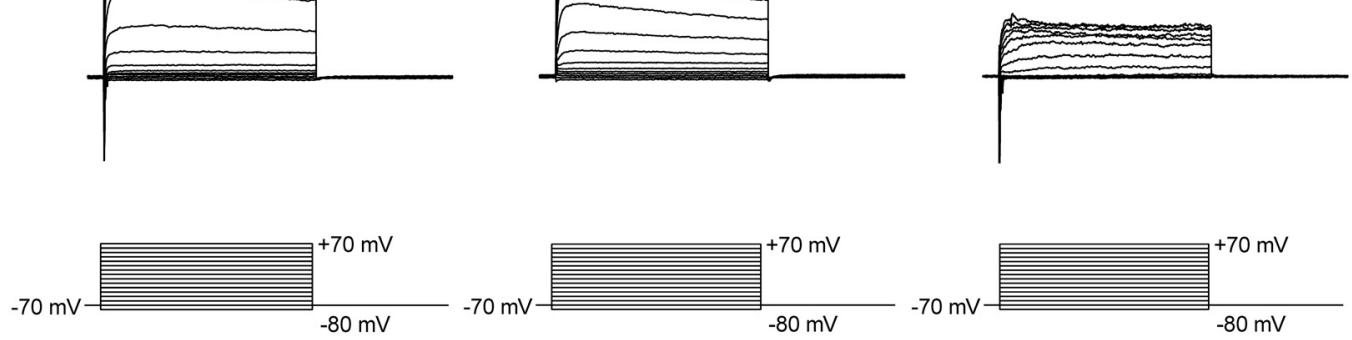

D

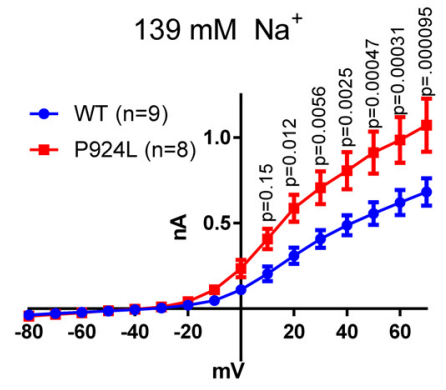

$\mathrm{E}$

E $\quad 0 \mathrm{Na}^{+}$

F Difference
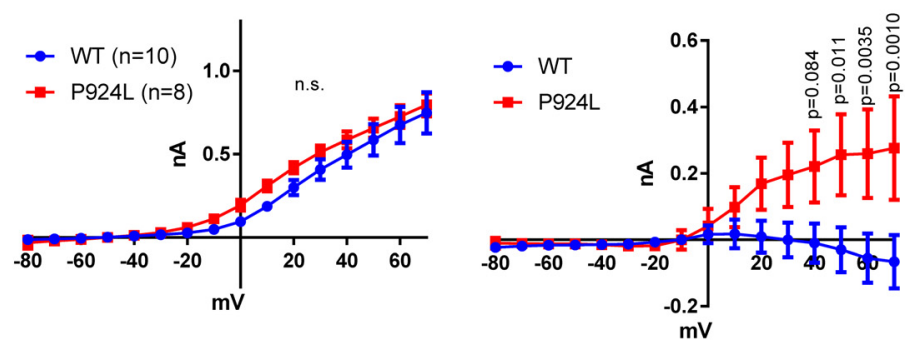

Figure 2. $K C N T 1$ P924L increases neuronal $\mathrm{K}_{\mathrm{Na}}$ currents. $\mathrm{K}_{\mathrm{Na}}$ currents were measured by recording outward currents in the presence or absence of extracellular sodium. $\boldsymbol{A}, \boldsymbol{D}$, Voltage-clamp recordings of Slack P924L cells have a larger steady-state outward current when sodium is present, consistent with an increased $\mathrm{K}_{\mathrm{Na}}$ current. $\boldsymbol{B}, \boldsymbol{E}$, In the condition where extracellular sodium is removed, the outward current for P924L neurons is no longer different from that in WT neurons. $C, F$, The difference current, a measure of $\mathrm{K}_{\mathrm{Na}}$, is substantially larger in P924L than WT, as would be expected for increased Slack channel activity. Significance values shown are from Student's $t$ test with Holm-Sidak correction for multiple comparisons. n.s., non significant.

dent throughout the train (Fig. 3C). When current steps were able to evoke more than one action potential in a WT neuron, the differences in width and subsequent afterhyperpolarization that were quantified for the first action potential in control and $\mathrm{P} 924 \mathrm{~L}$ Slack cells were also evident for these later action potentials. Figure $3 D$ shows examples of such later action potentials that occurred at the same time following the onset of depolarization of a WT and a P924L Slack neuron.

\section{Later maturation Slack P924L neurons continue to display increased AHP and firing rates}

The initial recordings suggested an early stage of neuronal maturation based on observations of short, infrequent action potentials (Sun et al., 2016). Recordings were repeated (Fig. 4) at a later maturation stage (DIV 14-16 after plating), going as late as possible before cell attachment began to be compromised. Intracellular and extracellular solutions as well as the protocol for current clamp were unchanged. In these cells, there was still no significant difference in the voltage threshold for activation $(-27.1 \pm 2.3$ $\mathrm{mV}$ for WT, $-31.6 \pm 1.5 \mathrm{mV}$ for P924L, $p=0.10, n=30)$. Narrowing of the action potential displayed enough variance that there was no longer a significant difference in width $(7.57 \pm 1.1$ $\mathrm{mV}$ for WT, $5.38 \pm 0.66 \mathrm{mV}$ for P924L, $p=0.09, n=30)$. There was a borderline difference in the height of the first AP for the more mature cells $(72.4 \pm 2.0 \mathrm{mV}$ for $\mathrm{WT}, 80.5 \pm 3.2 \mathrm{mV}$ for P924L, $p=0.047$ ). This did not appear to be highly significant as evident from the degree of scatter. The most prominent difference in shape was that the AHP depth remained substantially increased with the mutation $(4.7 \pm 1.1 \mathrm{mV}$ for WT, $11.0 \pm 1.4$ $\mathrm{mV}$ for P924L, $p=0.001, n=30)$. Spike counts elicited by a voltage stimulus remained more frequent with the mutation. The maximum number of spikes elicited per pulse in an individual cell was a median of 1 , mean of 1.9 in WT and median of 5 , mean of 4.1 for P924L ( $p=0.009, n=30$, Mann-Whitney $U$ tset).

\section{Increased AHP from P924L Slack neurons persists with block of BK or Kvl channels}

The simplest interpretation of the increase in AHPs in P924L Slack neurons is that the increase in AHP is caused directly by the increase in Slack current. Because there is no specific blocker of Slack channels, this could not be tested directly. It is possible, however, that the increased AHPs could result from adaptive 
A
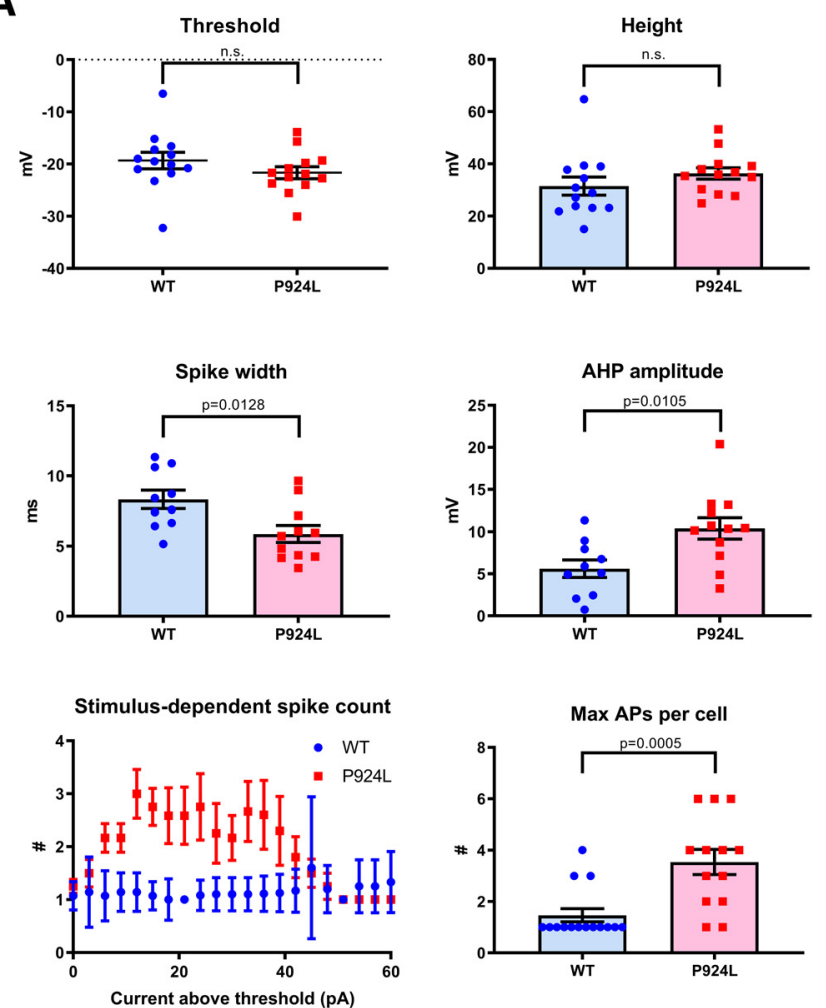

B
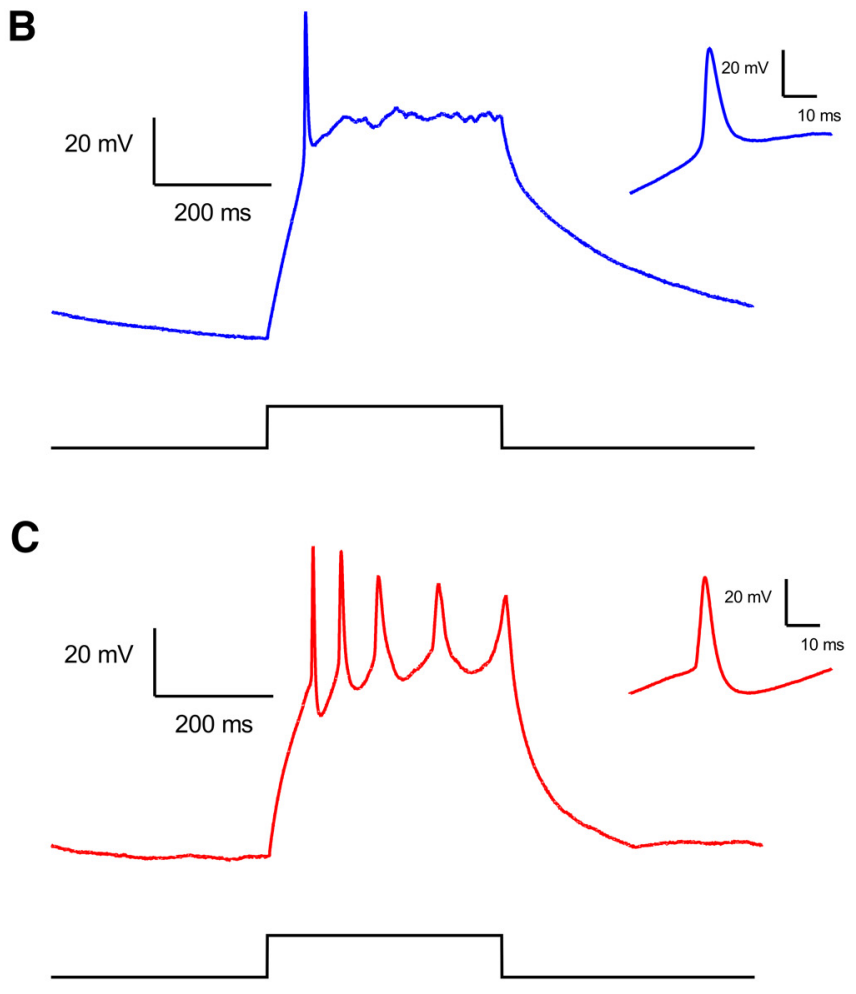

Figure 3. Changes in action potential caused by Slack P924L support neuronal hyperexcitability at DIV 7-8. A, Current-clamp recordings of Slack P924L cells have similar action potential thresholds and heights as WT cells but shorter spike width and deeper afterhyperpolarizations. P924L cells generate more action potentials over a range of currents. The maximum number of action potentials generated by each cell is higher for P924L. B, C, Sample current-clamp recordings in response to an inward current step stimulus demonstrate that WT neurons have a single action potential followed by minimal afterhyperpolarization $(\boldsymbol{B})$, whereas P924L neurons have prominent afterhyperpolarization allowing the cell to fire multiple action potentials by bringing the voltage back below threshold ( $\boldsymbol{C}$. Significance values shown are from Student's $t$ test. Whisker plots represent SDs and error bars for stimulus-dependent spike counts (A, lower left) represent SEM. n.S., non significant.

changes in other $\mathrm{K}^{+}$currents known to contribute to the fast AHP in neurons, specifically $\mathrm{Ca}^{2+}$-activated BK currents or $\mathrm{Kv} 1.1 / \mathrm{Kv} 1.2$ voltage-dependent currents. To test this possibility, we repeated the current-clamp experiments on cells at DIV 8-9 in the presence of blockers of these channels (Fig. 5). In the presence of $2 \mathrm{~mm}$ paxilline, a BK antagonist (Zhou and Lingle, 2011, 2014) that has no effect on Slack currents (de Los Angeles Tejada et al., 2012), WT cells had an AHP amplitude $5.5 \pm 1.6 \mathrm{mV}(n=$ $11)$ vs $13.6 \pm 2.0 \mathrm{mV}(n=15)$ for P924L, again significantly different $(p=0.007)$. $\alpha$-dendrotoxin is a blocker of Kv1.1 and Kv1.2, major voltage-dependent $\mathrm{K}^{+}$channels in the CNS, as well as of Kv1.6 (Wang et al., 1998; Harvey and Robertson, 2004). In the presence of $100 \mu \mathrm{M} \alpha$-dendrotoxin, WT cells had an AHP amplitude of $4.0 \pm 0.9 \mathrm{mV}(n=11)$ and mutant cells had an AHP of $9.9 \pm 1.0 \mathrm{mV}(n=14)$, which was again significantly different from WT ( $p=0.0004)$ (Fig. 5). These findings indicate that compensatory increases in BK or Kv1 channels in response to the P924L Slack mutations are unlikely to be a major factor in the increased AHP amplitude.

Numerical simulations of increased $\mathrm{K}_{\mathrm{Na}}$ current predict more numerous evoked action potentials.

Because activation of $\mathrm{K}^{+}$channels causes hyperpolarization of the plasma membrane, an increase in $\mathrm{K}^{+}$currents is often associated with reduced excitability. A clear exception to this is $\mathrm{K}^{+}$ channels that activate only at positive potentials, such as Kv3family of channels, for which increases in current promote highfrequency firing (Kaczmarek and Zhang, 2017). Although Slack channels are not strongly voltage-dependent, their dependence on $\mathrm{Na}^{+}$ions implies that maximal activation occurs during action potentials when $\mathrm{Na}^{+}$influx is maximal. To test the potential effects of an increase in Slack currents alone on neuronal firing, we performed numerical simulations on a simple neuron model that incorporated only a $\mathrm{Na}^{+}$current $I_{\mathrm{Na}}$, a leak current $I_{\mathrm{L}}$, a voltage-dependent $\mathrm{K}^{+}$current $I_{\mathrm{Kv}}$ and a Na${ }^{+}$- activated $\mathrm{K}^{+}$current $I_{\mathrm{KNa}}$. The kinetic parameters for the latter were based on previous recordings and simulations of $\mathrm{K}_{\mathrm{Na}}$ currents (Wang et al., 1998; Brown et al., 2008). The $\mathrm{Na}^{+}$concentration at the cytoplasmic face of the $\mathrm{K}_{\mathrm{Na}}$ channels was determined both by $\mathrm{Na}^{+}$entry through voltage-dependent $\mathrm{Na}^{+}$channels and by a steady-state leak of $\mathrm{Na}^{+}$ions into the cell, and these were balanced by a first order process of pumping intracellular $\mathrm{Na}^{+}$from the cell. The ratios of the conductances for $I_{\mathrm{Na}}, I_{\mathrm{L}}$, and $I_{\mathrm{Kv}}$ were adjusted to generate a single action potential in response to a step depolarization, similar to the responses for neurons in the 7-8 $\mathrm{d}$ after plating cortical cultures.

The effects of progressive increases in $I_{\mathrm{KNa}}$ are shown in Figure $6 A$, which shows both the firing response and the accompanying changes in intracellular $\mathrm{Na}^{+}$levels under the plasma membrane. With the introduction of low $\mathrm{K}_{\mathrm{Na}}$ currents, model neurons began to display a small fast afterhypolarization response. The most evident change in firing patterns in response to small increases in $I_{\mathrm{KNa}}$ was a progressive increase in the amplitude of the afterhyperpolarization following each action potential. As $I_{\mathrm{KNa}}$ was increased, an after-depolarization emerged following the initial spike. Finally, as $I_{\mathrm{KNa}}$ was further increased, repetitive firing was evoked throughout the duration of the depolarizing pulse. Thus, the changes in firing patterns observed in the iPSC-derived neu- 
A
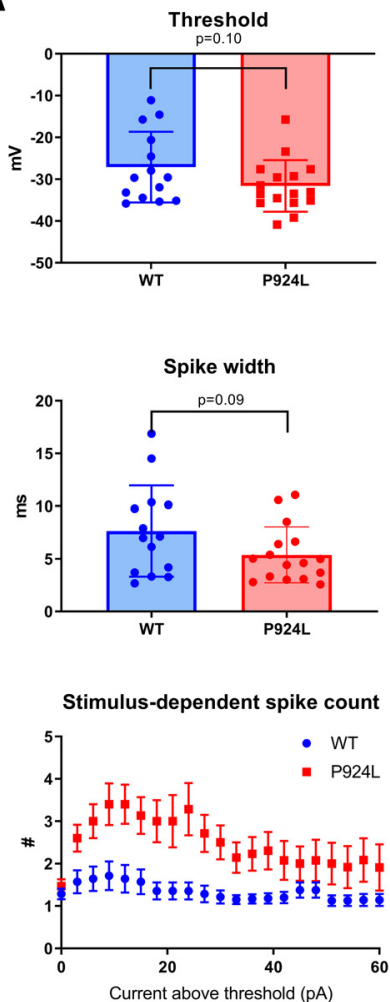
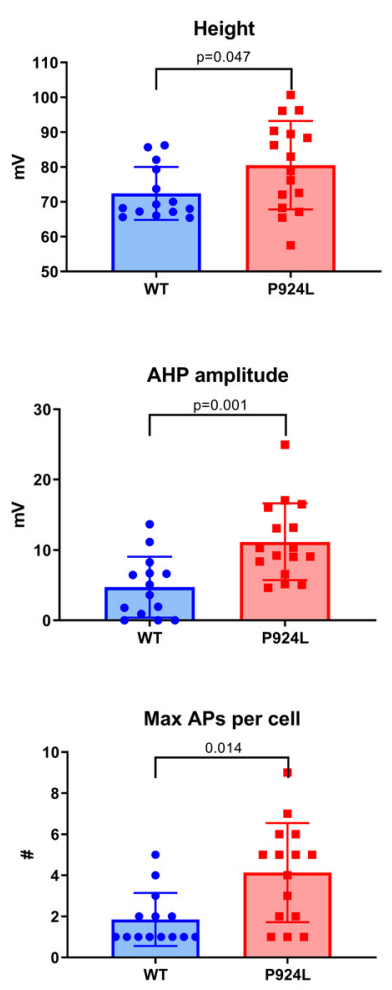

B

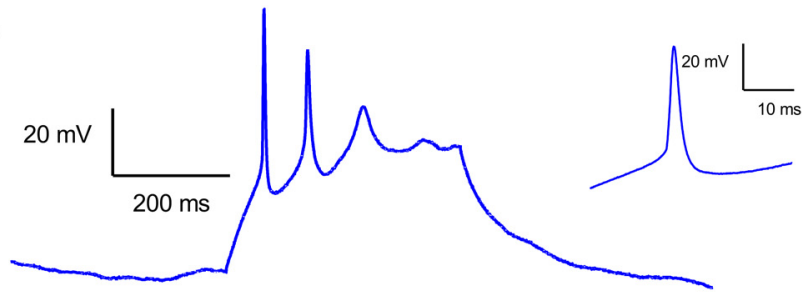

C
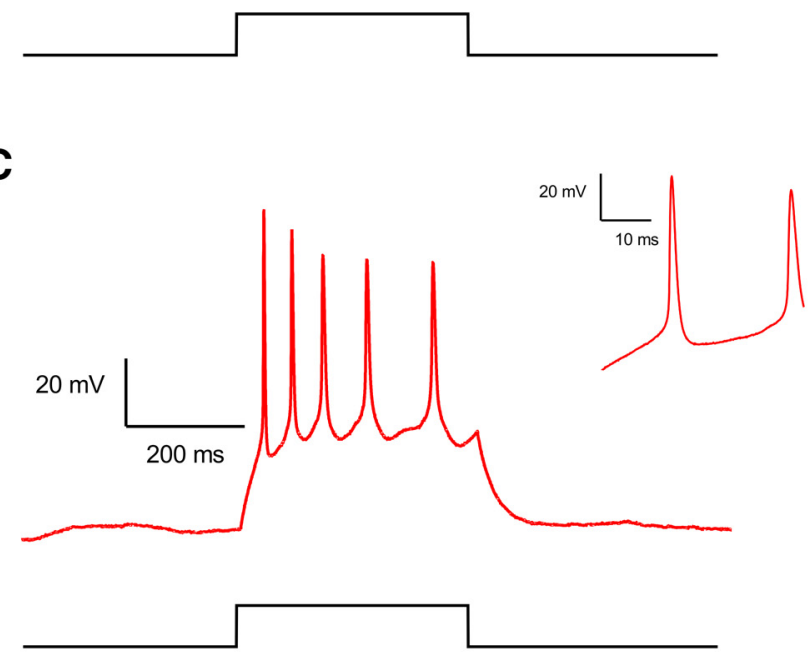

Figure 4. Current-clamp recordings of later-stage P924L-expressing IPS-derived neurons continue to display a hyperexcitable phenotype. $A$, Changes in the shape of the first threshold action potential caused by Slack P924L at DIV 14-16. A, Current-clamp recordings of Slack P924L cells have similar AP thresholds but deeper after hyperpolarization. P924L cells generate more action potentials in response to a stimulus over a range of current amplitudes and have a larger number of maximum elicitable spikes. Data shown as mean $\pm S D$ except for stimulus dependent spike count, which is SEM. B, Typical WT cells elicit a mean of two spikes. C, Typical P924L cells, in this case with the same current of $15 \mathrm{pA}$ above baseline as the example in $\boldsymbol{B}$, demonstrate a mean of more than four spikes.

rons are compatible with those expected from elevated $\mathrm{K}_{\mathrm{Na}}$ currents.

Figure $6 B$ shows the time course of activation of $I_{\mathrm{Na}}$, intracellular $\mathrm{Na}^{+}$, the $\mathrm{Na}^{+}$- activated $I_{\mathrm{KNa}}$ current, the voltagedependent current $I_{\mathrm{Kv}}$ and the leak current $I_{\mathrm{L}}$ for a simulation with a low and high value of $\mathrm{K}_{\mathrm{Na}}$ conductance. Resting membrane potential was the same in both conditions. The emergence of repetitive firing is seen to be associated with the progressive accumulation of $\mathrm{Na}^{+}$and $\mathrm{K}_{\mathrm{Na}}$ current. Figure $6, C$ and $D$, shows changes in spike threshold, height, width, and depth of afterhyperpolarizations for the simulations of Figure $6 \mathrm{~A}$. As with the P924L Slack cells, the emergence of sustained firing was associated with a marked increase in spike afterhyperpolarizations.

\section{Slack P924L increases aggregate spontaneous firing rates, burst behaviors, and synchrony}

To record the simultaneous activity of multiple neurons in a dense synaptically connected network, cells were plated as highdensity clusters of $\sim 60,000$ cells on MEAs. Control $(n=24)$ and P924L $(n=24)$ cells exhibited spontaneous firing and, in both types of clusters, repeated bursts of action potentials were evident (Fig. 7). Overall, Slack P924L-expressing cells had an increased mean firing rate $(0.360 \pm 0.037 \mathrm{~Hz}$ for WT, $0.554 \pm 0.064 \mathrm{~Hz}$ for P924L, $p=0.0116)$. The characteristics of the bursts of firing were also substantially different between the two cell types. Bursts were detected using a Poisson surprise analysis (Legéndy and Salcman, 1985). The frequency of these bursts was more than doubled by the mutation $(4.09 \pm 0.48$ bursts/min for WT, $10.44 \pm 1.50$ bursts/min for P924L, $p=0.0002$ ). Moreover, the spike rate within each burst (burst intensity) was increased for P924L-Slack cells $(6.42 \pm 0.58 \mathrm{~Hz}$ for WT, $8.66 \pm 0.69 \mathrm{~Hz}$ for P924L Slack, $p=0.0174)$, but burst durations were shorter $(3.26 \pm 0.39 s$ for WT, $1.70 \pm 0.20 s$ for P924L, $p=0.0009)$. In addition, we measured the synchrony of activity between electrodes in each well and found that synchrony index values [0-1] were increased by $>60 \%$ in recordings of P924L activity relative to WT $\left(1.037 \times 10^{-2} \pm 0.09610^{-2}\right.$ for WT vs $1.690 \times 10^{-2} \pm$ $0.178 \times 10^{-2}$ for P924L $(p=0.0023)$.

\section{Discussion}

Human iPSC-derived neurons have a $\mathrm{Na}^{+}$-dependent $\mathrm{K}^{+}$current that is substantially enhanced by the MMPSI-associated KCNT1 P924L mutation. Previous work demonstrated gain-offunction of the Slack current using heterologous expression of this and other epilepsy-associated mutations in Xenopus oocytes (Barcia et al., 2012; Kim et al., 2014; Milligan et al., 2014). Our findings provide direct evidence that neurons carrying an epilepsy associated Slack mutation also have an increased $\mathrm{K}_{\mathrm{Na}}$ current. The demonstration of a hyperexcitable phenotype for this mutation underscores the impact iPSCs can provide when investigating neurological disorders within their native milieu. Action potentials in these neurons are shorter and are followed by a larger fast afterhyperpolarization. The effects on this afterhyperpolarization are preserved in the presence of BK and Kv1 channel antagonists. In response to a maintained inward current, cells with the mutation can sustain more action potentials. It is likely that the increased afterhyperpolarizations accelerate recovery from the refractory period after each action potential, allowing 
A

aDTX

WT

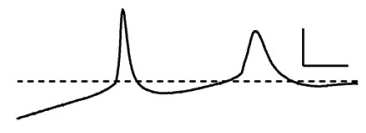

P924L

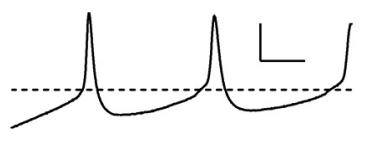

paxilline
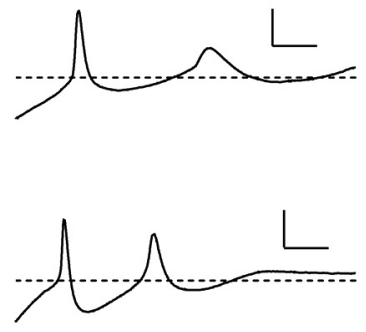

B

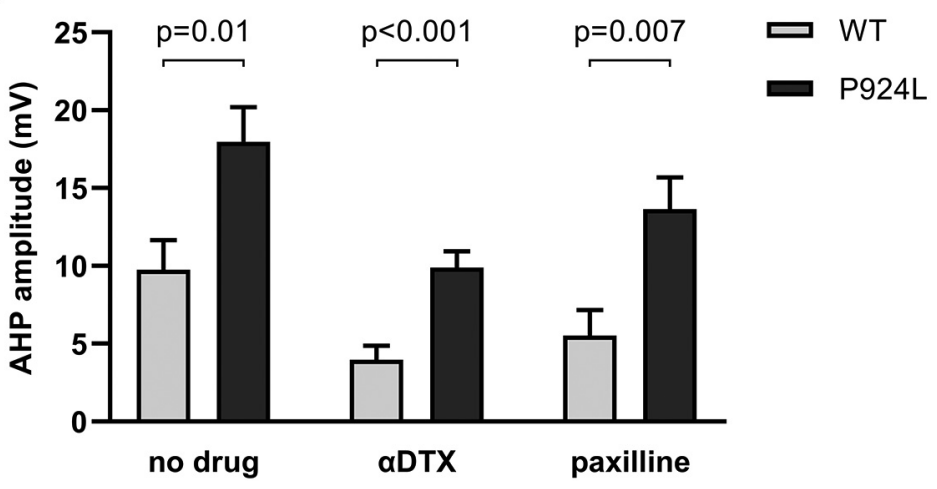

Figure 5. Changes in afterhyperpolarization associated with the Slack P924L mutation are maintained in the presence of antagonists to other potassium channels. $\boldsymbol{A}$, Representative current-clamp recordings in response to current steps from Slack WT and P924L neurons in the presence of $100 \mu \mathrm{m} \alpha$-dendrotoxin, a Kv1.1/Kv1.2/Kv1.6 antagonist, or 2 mm paxilline, a BK antagonist. The threshold of the first action potential is marked with a dashed line. Scale bars, $20 \mathrm{mV}$ and $20 \mathrm{~ms}$. $\boldsymbol{B}$, Group data from multiple cells in a control solution and with either drug added to the extracellular solution. Significance values are derived from two-tailed Student's $t$ tests.

generation of additional spikes. The findings of the multielectrode array experiments, including increased burst frequency and intensity, also support the observation that neurons that express the mutant Slack channel have increased intrinsic excitability. The cells in these experiments appeared to be at an early maturational stage as indicated by the height of the action potentials and limited firing. Because MMPSI is an early onset neurodevelopmental disorder, these early excitable properties of neuronal maturation may more accurately represent a model of the disease than more mature neuronal membrane properties.

There are two general possible explanations for the increase in excitability in cells expressing the gain-of-function P924L Slack mutation. One explanation is that the increased $\mathrm{K}_{\mathrm{Na}}$ current is directly responsible for increased firing rate. At first sight, this might appear counterintuitive because an increased potassium conductance is usually associated with lower excitability, the reverse of what is observed in epilepsy. Our numerical simulations of a very simple neuronal model, however, clearly demonstrate that an increase in the amplitude of afterhyperpolarizations, coupled with an increase in the numbers of actions potentials evoked by a depolarizing stimulus is indeed produced by an increase in Slack conductance with no changes in any other parameter. The major assumption made in this simple model is that Slack channels are activated rapidly by $\mathrm{Na}^{+}$entry though voltagedependent $\mathrm{Na}^{+}$channels. This is supported by experimental evidence demonstrating that $\mathrm{K}_{\mathrm{Na}}$ currents are activated within milliseconds of onset of an action potential or of AMPAmediated synaptic currents and that $\mathrm{K}_{\mathrm{Na}}$ channels cluster with $\mathrm{Na}^{+}$channels at nodes of myelinated axons (Koh et al., 1994;

Hess et al., 2007; Nanou et al., 2008). This rapid transient activation of $\mathrm{K}_{\mathrm{Na}}$ currents is kinetically distinct from slower components that have also been detected during neuronal firing and that are activated by persistent $\mathrm{Na}^{+}$channels (Budelli et al., 2009; Hage and Salkoff, 2012; Kaczmarek, 2013).

The simulations we have described should not be considered to represent a biophysically realistic model, nor an attempt to faithfully represent the detailed behavior of the cells. They incorporate only $\mathrm{Na}^{+}, \mathrm{Kv}$ and channels with no other active conductances. They have been highly simplified to illustrate the concept that high $\mathrm{K}_{\mathrm{Na}}$ currents can lead to hyperexcitability. With any multiparametric model, and particularly a nonlinear one, the results are sure to depend greatly on the parameter set and initial conditions. This has been shown for example with BK channels (Montgomery and Meredith, 2012; Whitt et al., 2016), in which gain of function of a $\mathrm{K}_{\mathrm{Ca}}$ current could either increase or decrease neuronal firing based on other parameters (in that case, associated with time of day in suprachiasmatic nucleus neurons). Despite the limitations, our simple model yielded the results shown without any parameter tuning and shows that it is in theory feasible for high $\mathrm{K}_{\mathrm{Na}}$ currents (associated with increased fast AHP) to increase neuronal firing frequency, similar to our experimental observations. The principal constraint of the model is that $\mathrm{Na}^{+}$entry during the action potential must activate the $\mathrm{K}_{\mathrm{Na}}$ channels sufficiently rapidly to contribute to the fast AHP.

An alternative explanation for increased excitability is that the presence of mutant channels induces compensatory changes in other conductances. Although we found no changes to $\mathrm{Na}_{\mathrm{V}} \mathrm{l}$, Kv1.1 or BK channel levels in neurons expressing the mutation, and the changes in AHP were preserved with blocking Kvl family and BK conductances, we cannot eliminate the possibility of changes in other channel pore-forming subunits, their auxiliary subunits, or in enzymes that could influence these proteins. Such compensatory changes could explain the minor differences in the effects of the mutation at the two developmental stages we studied. Moreover, Slack channels interact with components of cell signaling pathways such as Phactr-1 and FMRP (Brown et al., 2010; Zhang et al., 2012; Fleming et al., 2016) and these interactions could be disrupted by the mutation. Understanding the potential consequences of such cellular alterations, which may result in changes beyond altered excitability, will likely require animal models rather than iPSC-derived neurons. Indeed there is evidence that compensatory changes in neurons with epilepsyassociated ion channel mutations contribute to pathology-for example loss of Nav1.1 channel activity leads to SK channel downregulation and increased thalamic bursting (RitterMakinson et al., 2019). Such compensatory changes might additionally influence treatment options (Isom, 2019). Nevertheless, the finding that the altered excitability in neurons with the P924L mutation closely matches that seen in simple model simulations 
A

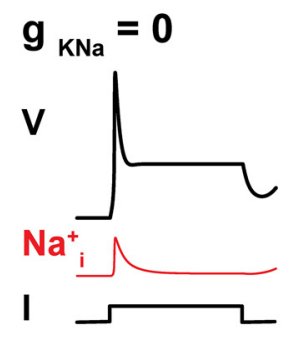

$$
\mathbf{g}_{\mathrm{KNa}}=\mathbf{3 . 0}
$$

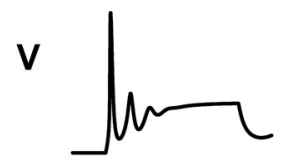

$\mathrm{Na}^{+}$

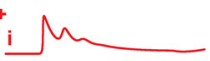

I
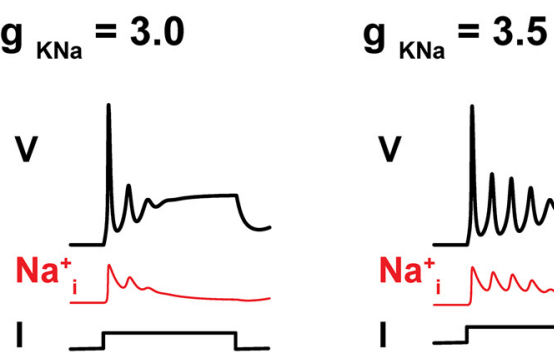

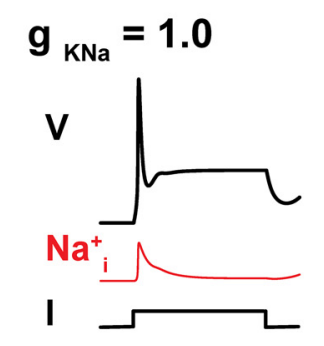

B

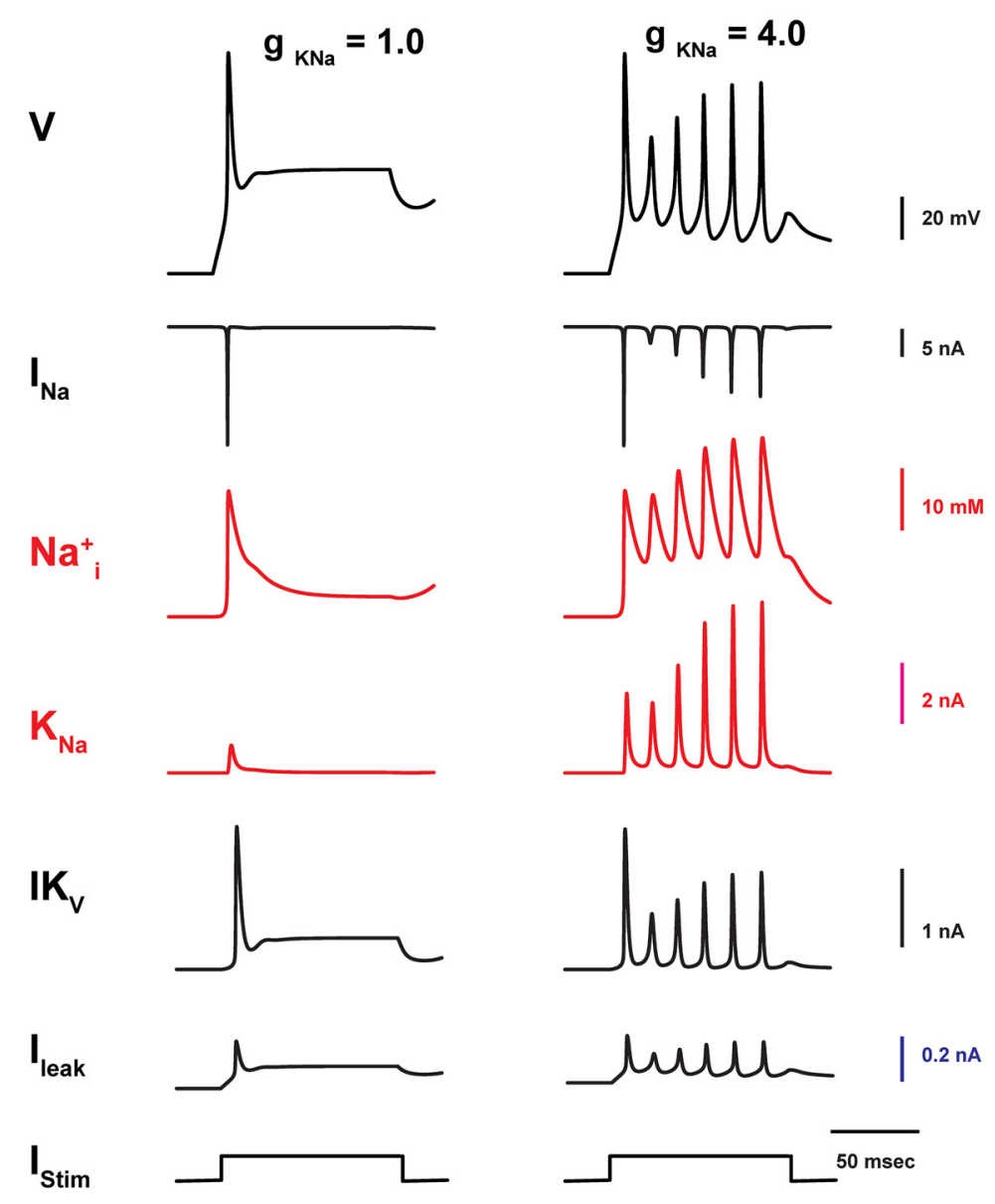

C

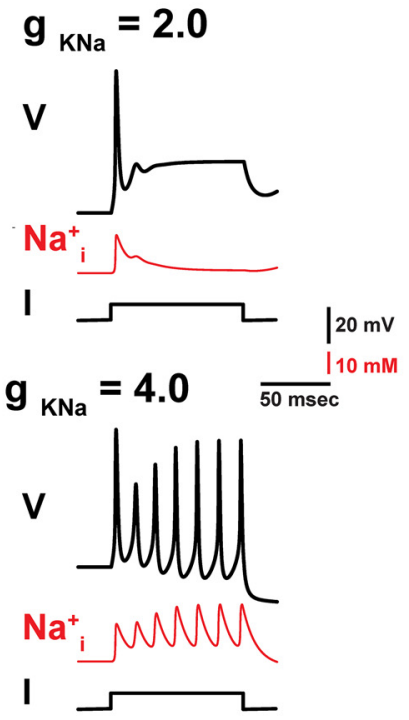

D
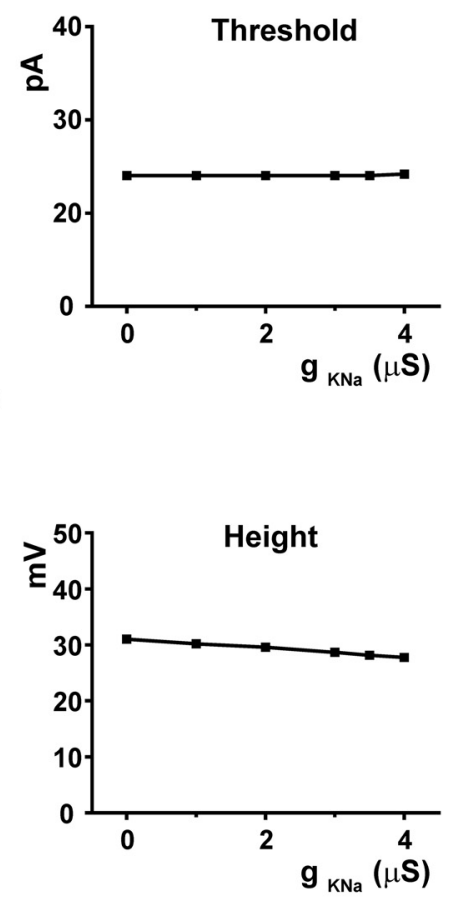

E

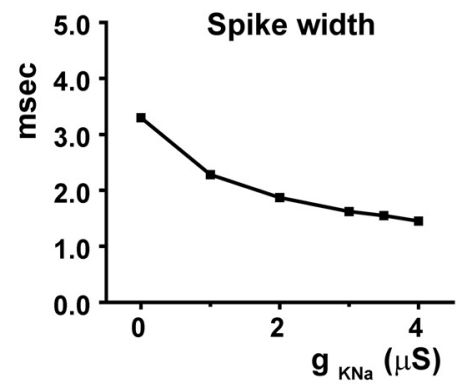

F

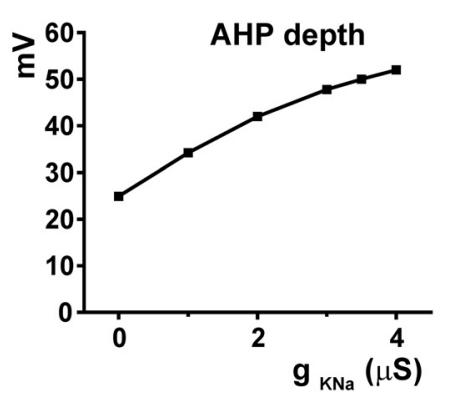

Figure 6. Numerical simulations of the effect of increasing Slack $\mathrm{K}_{\mathrm{Na}}$ conductance in a simplified model neuron while holding other parameters constant. $A$, Progressively increasing the $\mathrm{K}_{\mathrm{Na}}$ current increases afterhyperpolarizations and eventually trigger repetitive firing during maintained depolarization. $\boldsymbol{B}$, Time course of membrane potential, $I_{\mathrm{Na},}$ intracellular Na ${ }^{+}, I_{\mathrm{KNa}}, I_{\mathrm{Kv}}$ and the leak current $I_{L}$ for a simulation with a low and high value of $\mathrm{K}_{\mathrm{Na}}$ conductance. $\boldsymbol{C}, \boldsymbol{D}$, Action potential activation thresholds $(\boldsymbol{C})$ and height $(\boldsymbol{D})$ show minimal changes. There is a progressive decrease in spike width $(\boldsymbol{E})$ and increase in AHP depth $(\boldsymbol{F})$ as the maximum $\mathrm{K}_{\mathrm{Na}}$ conductance is increased. Thresholds were measured as the minimal stimulating current that triggered an action potential. Action potential height was measured as the membrane potential at the peak. Width was measured at $0 \mathrm{mV}$, and AHP depth was measured at the most negative membrane potential reached following the first action potential. 


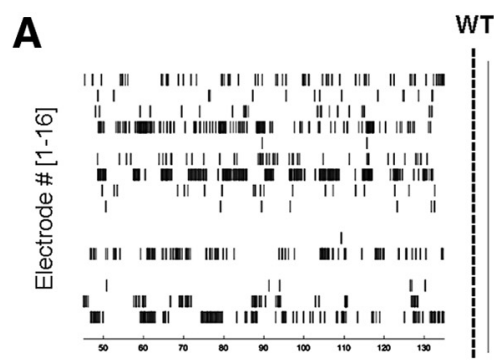

WT

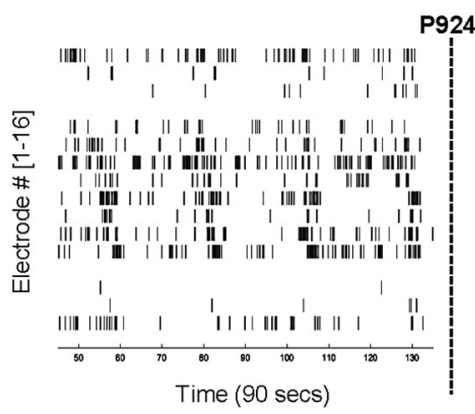

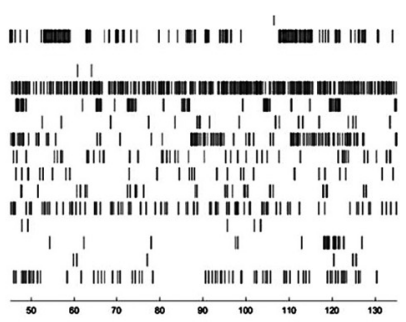

24L

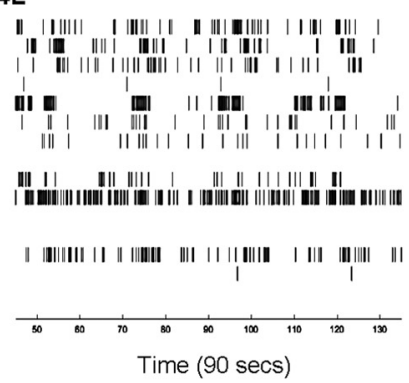

B
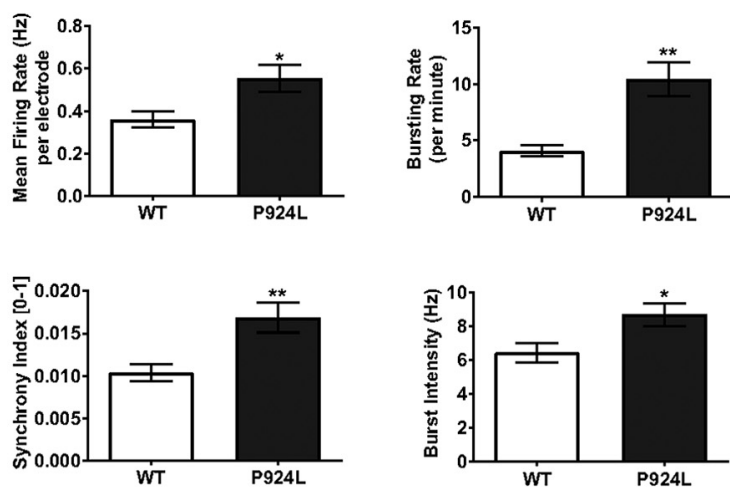

${ }^{*}=p<0.05$
${ }^{*}=p<0.01$

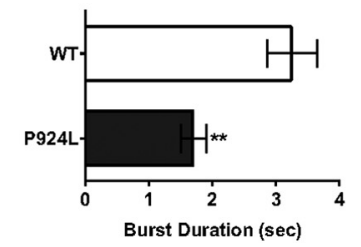

Figure 7. KCNT1 P924L increases aggregate firing rates, bursting behaviors, and firing synchrony. A, Raster plots of action potentials from MEA recordings of WT or KCNT1 P924L iPSC-derived neurons. Cells exhibit spontaneous firing and bursting behaviors on DIV 11. Two example wells of each condition are presented, with black tick marks denoting action potential (AP) timings across time $(90 \mathrm{~s})$ for all 16 electrodes within the well. Poisson burst statistics were used to capture and quantify momentary, high-frequency bursts. $\boldsymbol{B}$, Firing and bursting statistics averaged across all wells ( $n=24$ per group) show that Slack P924L increases the mean firing rate $(p<0.05)$ and synchrony $(p<0.01)$, with greater burst frequency $(p<0.01)$ and higher burst intensities $(p<0.05)$. Although bursts in P924L cells are more frequent and more intense, they have shorter durations $(p<0.01)$ than control. Error bars indicate SEM.

of increased $\mathrm{K}_{\mathrm{Na}}$ argues that the increase in this component of current alone is a major factor that increases excitability.

The multielectrode array results also suggest that the timing of firing in networks of neurons with the P924L Slack mutation is altered, producing an increase in measures of synchrony in the clusters, and increasing the overall activity of groups of neurons. Indeed, activation of Slack channels has previously been demonstrated to regulate the timing and accuracy of high-frequency firing of neurons in the auditory brainstem (Yang et al., 2007). Epilepsies associated with Slack mutations might, therefore, be considered disorders of hypersynchrony.

P924L is only one of many epilepsy-associated Slack mutations identified to date (Barcia et al., 2012; Heron et al., 2012; Kim et al., 2014; Martin et al., 2014; Milligan et al., 2014; Shimada et al., 2014; Møller et al., 2015; Mikati et al., 2015; Rizzo et al., 2016; Tang et al., 2016). Phenotypes cover a spectrum from severe infantile epilepsies (MMPSI or Ohtahara syndrome) to later-onset ADNFLE. Because these various mutations consistently show increased conductance when heterologously expressed, the mechanism of hyperexcitability demonstrated here is likely to be relevant regardless of the specific mutation. Similarly, specific inhibition of the Slack current would be expected to reduce hyperexcitability in any Slack-associated gain-of-function epilepsy.

Gain-of-function mutations in several other potassium channels have also been proposed to cause epilepsy, but the mechanism by which they lead to epilepsy is likely to differ. The most similar may be the BK channel (KCMA1), which has high structural similarity to Slack (Hite et al., 2015). Mutations that cause BK channels to open more, due to changes in either voltage dependence or calcium sensitivity, are known to cause epilepsy, often with paroxysmal dyskinesia (Du et al., 2005; Wang et al., 2009; Li et al., 2018). The mechanism is unknown but may parallel that for Slack, as both channels are cation-activated.

Another interesting parallel is Kv3.1 (KCNC1). This highthreshold channel is thought to speed up action potential recov- ery and promote rapid firing (Rudy and McBain, 2001; Labro et al., 2015; Kaczmarek and Zhang, 2017) similar to what we propose for mutant Slack. Within the cerebral cortex, these channels are expressed in inhibitory neurons, and loss-of-function point mutations cause progressive myoclonus epilepsy (Muona et al., 2015).

A limitation of the study is that we have only evaluated the P924L homozygous condition, whereas a heterozygous mutation is sufficient to cause human epilepsy. Although the use of cells with a homozygous mutation makes analysis more straightforward, heterozygous cells may behave differently, in part because of heteromer formation and other potential interactions between WT and P924L subunits. Nevertheless, even the effects of a single copy mutation in iPSC-derived cells could be very different from those of the same mutation in a developing brain.

In addition to producing early-onset seizures, Slack mutations are associated with severe intellectual disability (Kim and Kaczmarek, 2014). It is not yet clear to what extent this results from seizures themselves or from other cellular alterations. ADNFLE can be caused either by mutations in Slack or in the neuronal nicotinic acetylcholine receptor. The fact that reported cases of Slack-associated ADNFLE have much more severe neuropsychiatric/neurodevelopmental consequences than those caused by nicotinic acetylcholine receptor mutations suggests that Slack mutations impair development beyond simply triggering seizures (Steinlein et al., 1995; Heron et al., 2012). Nonconducting functions of Slack including protein-protein interactions with Phactr-1 and FMRP, which regulate RNA translation and other aspects of cellular signaling, may provide another pathological mechanism distinct from the direct effect of the mutations on hyperexcitability. Pharmacological treatments that address both aspects of channel function may prove the most therapeutically useful. 


\section{References}

Balan S, Toyoshima M, Yoshikawa T (2018) Contribution of induced pluripotent stem cell technologies to the understanding of cellular phenotypes in schizophrenia. Neurobiol Dis, In press.

Barcia G, Fleming MR, Deligniere A, Gazula VR, Brown MR, Langouet M, Chen H, Kronengold J, Abhyankar A, Cilio R, Nitschke P, Kaminska A, Boddaert N, Casanova JL, Desguerre I, Munnich A, Dulac O, Kaczmarek LK, Colleaux L, Nabbout R (2012) De novo gain-of-function KCNT1 channel mutations cause malignant migrating partial seizures of infancy. Nat Genet 44:1255-1259.

Bausch AE, Dieter R, Nann Y, Hausmann M, Meyerdierks N, Kaczmarek LK, Ruth P, Lukowski R (2015) The sodium-activated potassium channel Slack is required for optimal cognitive flexibility in mice. Learn Mem 22:323-335.

Berry BJ, Akanda N, Smith AS, Long CJ, Schnepper MT, Guo X, Hickman JJ (2015) Morphological and functional characterization of human induced pluripotent stem cell-derived neurons (iCell Neurons) in defined culture systems. Biotechnol Prog 31:1613-1622.

Bhattacharjee A, von Hehn CA, Mei X, Kaczmarek LK (2005) Localization of the $\mathrm{Na}+$-activated $\mathrm{K}+$ channel Slick in the rat central nervous system. J Comp Neurol 484:80-92.

Biton B, Sethuramanujam S, Picchione KE, Bhattacharjee A, Khessibi N, Chesney F, Lanneau C, Curet O, Avenet P (2012) The antipsychotic drug loxapine is an opener of the sodium-activated potassium channel Slack (Slo2.2). J Pharmacol Exp Ther 340:706-715.

Brown MR, Kronengold J, Gazula VR, Spilianakis CG, Flavell RA, Von Hehn CAA, Bhattacharjee A, Kaczmarek LK (2008) Amino-termini isoforms of the Slack $\mathrm{K}^{+}$channel, regulated by alternative promoters, differentially modulate rhythmic firing and adaptation. J Physiol 586:5161-5179.

Brown MR, Kronengold J, Gazula VR, Chen Y, Strumbos JG, Sigworth FJ, Navaratnam D, Kaczmarek LK (2010) Fragile X mental retardation protein controls gating of the sodium-activated potassium channel Slack. Nat Neurosci 13:819-821.

Budelli G, Hage TA, Wei A, Rojas P, Ivy Jong YJ, O’Malley K, Salkoff L (2009) $\mathrm{Na}^{+}$-activated $\mathrm{K}^{+}$channels express a large delayed outward current in neurons during normal physiology. Nat Neurosci 12:745-750.

Chai X, Dage JL, Citron M (2012) Constitutive secretion of tau protein by an unconventional mechanism. Neurobiol Dis 48:356-366.

Chatzidaki A, Fouillet A, Li J, Dage J, Millar NS, Sher E, Ursu D (2015) Pharmacological characterisation of nicotinic acetylcholine receptors expressed in human iPSC-derived neurons. PLoS One 10:e0125116.

Coppola G, Plouin P, Chiron C, Robain O, Dulac O (1995) Migrating partial seizures in infancy: a malignant disorder with developmental arrest. Epilepsia 36:1017-1024.

Csobonyeiova M, Polak S, Nicodemou A, Danisovic L (2017) Induced pluripotent stem cells in modeling and cell-based therapy of amyotrophic lateral sclerosis. J Physiol Pharmacol 68:649-657.

Dage JL, Colvin EM, Fouillet A, Langron E, Roell WC, Li J, Mathur SX, Mogg AJ, Schmitt MG, Felder CC, Merchant KM, Isaac J, Broad LM, Sher E, Ursu D (2014) Pharmacological characterisation of ligand- and voltagegated ion channels expressed in human iPSC-derived forebrain neurons. Psychopharmacology (Berl) 231:1105-1124.

de Los Angeles Tejada M, Stolpe K, Meinild AK, Klaerke DA (2012) Clofilium inhibits Slick and Slack potassium channels. Biologics 6:465-470.

Drawnel FM, et al. (2014) Disease modeling and phenotypic drug screening for diabetic cardiomyopathy using human induced pluripotent stem cells. Cell Rep 9:810-821.

Du W, Bautista JF, Yang H, Diez-Sampedro A, You SA, Wang L, Kotagal P, Lüders HO, Shi J, Cui J, Richerson GB, Wang QK (2005) Calciumsensitive potassium channelopathy in human epilepsy and paroxysmal movement disorder. Nat Genet 37:733-738.

Fleming MR, Brown MR, Kronengold J, Zhang Y, Jenkins DP, Barcia G, Nabbout R, Bausch AE, Ruth P, Lukowski R, Navaratnam DS, Kaczmarek LK (2016) Stimulation of Slack $\mathrm{K}^{+}$channels alters mass at the plasma membrane by triggering dissociation of a phosphatase-regulatory complex. Cell Rep 16:2281-2288.

Gonzalez DM, Gregory J, Brennand KJ (2017) The importance of nonneuronal cell types in hiPSC-based disease modeling and drug screening. Front Cell Dev Biol 5:117.

Hage TA, Salkoff L (2012) Sodium-activated potassium channels are functionally coupled to persistent sodium currents. J Neurosci 32:2714-2721.

Harvey AL, Robertson B (2004) Dendrotoxins: structure-activity relation- ships and effects on potassium ion channels. Curr Med Chem 11: 3065-3072.

Haythornthwaite A, Stoelzle S, Hasler A, Kiss A, Mosbacher J, George M, Brüggemann A, Fertig N (2012) Characterizing human ion channels in induced pluripotent stem cell-derived neurons. J Biomol Screen 17:1264-1272.

Heron SE, Smith KR, Bahlo M, Nobili L, Kahana E, Licchetta L, Oliver KL, Mazarib A, Afawi Z, Korczyn A, Plazzi G, Petrou S, Berkovic SF, Scheffer IE, Dibbens LM (2012) Missense mutations in the sodium-gated potassium channel gene KCNT1 cause severe autosomal dominant nocturnal frontal lobe epilepsy. Nat Genet 44:1188-1190.

Hess D, Nanou E, El Manira A (2007) Characterization of $\mathrm{Na}^{+}$-activated $\mathrm{K}^{+}$currents in larval lamprey spinal cord neurons. J Neurophysiol 97:3484-3493.

Hite RK, Yuan P, Li Z, Hsuing Y, Walz T, MacKinnon R (2015) Cryoelectron microscopy structure of the Slo2.2 $\mathrm{Na}^{+}$-activated $\mathrm{K}^{+}$channel. Nature 527:198-203.

Isom LL (2019) Is targeting of compensatory ion channel gene expression a viable therapeutic strategy for Dravet syndrome? Epilepsy Curr 19:193-195.

Kaczmarek LK (2012) Gradients and modulation of $\mathrm{K}^{+}$channels optimize temporal accuracy in networks of auditory neurons. PLoS Comput Biol 8:e1002424.

Kaczmarek LK (2013) Slack, Slick and sodium-activated potassium channels. ISRN Neurosci 2013:1-14.

Kaczmarek LK, Zhang Y (2017) Kv3 channels: enablers of rapid firing, neurotransmitter release, and neuronal endurance. Physiol Rev 97:14311468.

Kaczmarek LK, Aldrich RW, Chandy KG, Grissmer S, Wei AD, Wulff H (2017) International union of basic and clinical pharmacology. C. Nomenclature and properties of calcium-activated and sodium-activated potassium channels. Pharmacol Rev 69:1-11.

Kim GE, Kaczmarek LK (2014) Emerging role of the KCNT1 Slack channel in intellectual disability. Front Cell Neurosci 8:209.

Kim GE, Kronengold J, Barcia G, Quraishi IH, Martin HC, Blair E, Taylor JC, Dulac O, Colleaux L, Nabbout R, Kaczmarek LK (2014) Human Slack potassium channel mutations increase positive cooperativity between individual channels. Cell Rep 9:1661-1672.

Koh DS, Jonas P, Vogel W (1994) $\mathrm{Na}^{+}$-activated $\mathrm{K}^{+}$channels localized in the nodal region of myelinated axons of Xenopus. J Physiol 479:183-197.

Labro AJ, Priest MF, Lacroix JJ, Snyders DJ, Bezanilla F (2015) Kv3.1 uses a timely resurgent $\mathrm{K}^{+}$current to secure action potential repolarization. Nat Commun 6:10173.

LaMarca EA, Powell SK, Akbarian S, Brennand KJ (2018) Modeling neuropsychiatric and neurodegenerative diseases with induced pluripotent stem cells. Front Pediatr 6:82.

Legéndy CR, Salcman M (1985) Bursts and recurrences of bursts in the spike trains of spontaneously active striate cortex neurons. J Neurophysiol 53: 926-939.

Li X, Poschmann S, Chen Q, Fazeli W, Oundjian NJ, Snoeijen-Schouwenaars FM, Fricke O, Kamsteeg EJ, Willemsen M, Wang QK (2018) De novo BK channel variant causes epilepsy by affecting voltage gating but not $\mathrm{Ca}^{2+}$ sensitivity. Eur J Hum Genet 26:220-229.

Liu SQ, Kaczmarek LK (1998) Depolarization selectively increases the expression of the Kv3.1 potassium channel in developing inferior colliculus neurons. J Neurosci 18:8758-8769.

Liu Y, Lopez-Santiago LF, Yuan Y, Jones JM, Zhang H, O'Malley HA, Patino GA, O’Brien JE, Rusconi R, Gupta A, Thompson RC, Natowicz MR, Meisler MH, Isom LL, Parent JM (2013) Dravet syndrome patientderived neurons suggest a novel epilepsy mechanism. Ann Neurol 74: $128-139$.

Lu R, Bausch AE, Kallenborn-Gerhardt W, Stoetzer C, Debruin N, Ruth P, Geisslinger G, Leffler A, Lukowski R, Schmidtko A (2015) Slack channels expressed in sensory neurons control neuropathic pain in mice. J Neurosci 35:1125-1135.

Macica CM, von Hehn CA, Wang LY, Ho CS, Yokoyama S, Joho RH, Kaczmarek LK (2003) Modulation of the Kv3.1b potassium channel isoform adjusts the fidelity of the firing pattern of auditory neurons. J Neurosci 23:1133-1141.

Martin HC, et al. (2014) Clinical whole-genome sequencing in severe earlyonset epilepsy reveals new genes and improves molecular diagnosis. Hum Mol Genet 23:3200-3211. 
Mikati MA, Jiang YH, Carboni M, Shashi V, Petrovski S, Spillmann R, Milligan CJ, Li M, Grefe A, McConkie A, Berkovic S, Scheffer I, Mullen S, Bonner M, Petrou S, Goldstein D (2015) Quinidine in the treatment of KCNT1-positive epilepsies. Ann Neurol 78:995-999.

Milligan CJ, Li M, Gazina EV, Heron SE, Nair U, Trager C, Reid CA, Venkat A, Younkin DP, Dlugos DJ, Petrovski S, Goldstein DB, Dibbens LM, Scheffer IE, Berkovic SF, Petrou S (2014) KCNT1 gain of function in 2 epilepsy phenotypes is reversed by quinidine. Ann Neurol 75:581-590.

Møller RS, et al. (2015) Mutations in KCNT1 cause a spectrum of focal epilepsies. Epilepsia 56:e114-e120.

Montgomery JR, Meredith AL (2012) Genetic activation of BK currents in vivo generates bidirectional effects on neuronal excitability. Proc Natl Acad Sci U S A 109:18997-19002.

Muona M, et al. (2015) A recurrent de novo mutation in KCNC1 causes progressive myoclonus epilepsy. Nat Genet 47:39-46.

Nanou E, Kyriakatos A, Bhattacharjee A, Kaczmarek LK, Paratcha G, El Manira A (2008) $\mathrm{Na}^{+}$-mediated coupling between AMPA receptors and $\mathrm{KNa}$ channels shapes synaptic transmission. Proc Natl Acad Sci U S A 105:20941-20946.

Nuwer MO, Picchione KE, Bhattacharjee A (2010) PKA-induced internalization of Slack $\mathrm{K}_{\mathrm{Na}}$ channels produces dorsal root ganglion neuron hyperexcitability. J Neurosci 30:14165-14172.

Ohba C, et al. (2015) De novo KCNT1 mutations in early-onset epileptic encephalopathy. Epilepsia 56:e121-e128.

Paiva ARC, Park I, Príncipe JC (2010) A comparison of binless spike train measures. Neural Comput Appl 19:405-419.

Richardson FC, Kaczmarek LK (2000) Modification of delayed rectifier potassium currents by the Kv9.1 potassium channel subunit. Hear Res 147:21-30.

Ritter-Makinson S, Clemente-Perez A, Higashikubo B, Cho FS, Holden SS, Bennett E, Chkhaidze A, Eelkman Rooda OHJ, Cornet MC, Hoebeek FE, Yamakawa K, Cilio MR, Delord B, Paz JT (2019) Augmented reticular thalamic bursting and seizures in Scnla-Dravet syndrome. Cell Rep 26:54-64.e6.

Rizzo F, Ambrosino P, Guacci A, Chetta M, Marchese G, Rocco T, Soldovieri MV, Manocchio L, Mosca I, Casara G, Vecchi M, Taglialatela M, Coppola G, Weisz A (2016) Characterization of two de novo KCNT1 mutations in children with malignant migrating partial seizures in infancy. Mol Cell Neurosci 72:54-63.

Rudy B, McBain CJ (2001) Kv3 channels: voltage-gated $\mathrm{K}^{+}$channels designed for high-frequency repetitive firing. Trends Neurosci 24:517-526.

Santi CM, Ferreira G, Yang B, Gazula VR, Butler A, Wei A, Kaczmarek LK, Salkoff L (2006) Opposite regulation of Slick and Slack $\mathrm{K}^{+}$channels by neuromodulators. J Neurosci 26:5059-5068.

Shimada S, Hirano Y, Ito S, Oguni H, Nagata S, Shimojima K, Yamamoto T (2014) A novel KCNT1 mutation in a Japanese patient with epilepsy of infancy with migrating focal seizures. Hum Genome Var 1:14027.

Song P, Yang Y, Barnes-Davies M, Bhattacharjee A, Hamann M, Forsythe ID,
Oliver DL, Kaczmarek LK (2005) Acoustic environment determines phosphorylation state of the Kv3.1 potassium channel in auditory neurons. Nat Neurosci 8:1335-1342.

Steinlein OK, Mulley JC, Propping P, Wallace RH, Phillips HA, Sutherland GR, Scheffer IE, Berkovic SF (1995) A missense mutation in the neuronal nicotinic acetylcholine receptor alpha 4 subunit is associated with autosomal dominant nocturnal frontal lobe epilepsy. Nat Genet 11: 201-203.

Sun Y, Pașca SP, Portmann T, Goold C, Worringer KA, Guan W, Chan KC, Gai H, Vogt D, Chen YJ, Mao R, Chan K, Rubenstein JL, Madison DV, Hallmayer J, Froehlich-Santino WM, Bernstein JA, Dolmetsch RE (2016) A deleterious Nav1.1 mutation selectively impairs telencephalic inhibitory neurons derived from Dravet syndrome patients. Elife 5:e13073.

Tamsett TJ, Picchione KE, Bhattacharjee A (2009) NAD+ activates KNa channels in dorsal root ganglion neurons. J Neurosci 29:5127-5134.

Tang QY, Zhang F-FF, Xu J, Wang R, Chen J, Logothetis DE, Zhang Z (2016) Epilepsy-related slack channel mutants lead to channel over-activity by two different mechanisms. Cell Rep 14:129-139.

Tidball AM, Parent JM (2016) Concise review: exciting cells: modeling genetic epilepsies with patient-derived induced pluripotent stem cells. Stem Cells 34:27-33.

Vanderver A, Simons C, Schmidt JL, Pearl PL, Bloom M, Lavenstein B, Miller D, Grimmond SM, Taft RJ (2014) Identification of a novel de novo p.Phe932Ile KCNT1 mutation in a patient with leukoencephalopathy and severe epilepsy. Pediatr Neurol 50:112-114.

Wang B, Rothberg BS, Brenner R (2009) Mechanism of increased BK channel activation from a channel mutation that causes epilepsy. J Gen Physiol 133:283-294.

Wang LY, Gan L, Forsythe ID, Kaczmarek LK (1998) Contribution of the Kv3.1 potassium channel to high-frequency firing in mouse auditory neurones. J Physiol 509:183-194.

Whitt JP, Montgomery JR, Meredith AL (2016) BK channel inactivation gates daytime excitability in the circadian clock. Nat Commun 7:10837.

Yang B, Desai R, Kaczmarek LK (2007) Slack and Slick $\mathrm{K}_{\mathrm{Na}}$ channels regulate the accuracy of timing of auditory neurons. J Neurosci 27: 2617-2627.

Yuan A, Santi CM, Wei A, Wang ZW, Pollak K, Nonet M, Kaczmarek L, Crowder CM, Salkoff L (2003) The sodium-activated potassium channel is encoded by a member of the Slo gene family. Neuron 37:765-773.

Zhang Y, Brown MR, Hyland C, Chen Y, Kronengold J, Fleming MR, Kohn AB, Moroz LL, Kaczmarek LK (2012) Regulation of neuronal excitability by interaction of fragile $\mathrm{X}$ mental retardation protein with Slack potassium channels. J Neurosci 32:15318-15327.

Zhou Y, Lingle CJ (2011) Paxilline, a closed BK channel blocker. Biophys J 100:261a-262a.

Zhou Y, Lingle CJ (2014) Paxilline inhibits BK channels by an almost exclusively closed-channel block mechanism. J Gen Physiol 144:415-440. 